\title{
Special Interests and the Media: Theory and an Application to Climate Change
}

\author{
Jesse M. Shapiro* \\ Brown University and NBER
}

September 2016

\begin{abstract}
A journalist reports to a voter on an unknown, policy-relevant state. Competing special interests can make claims that contradict the facts but seem credible to the voter. A reputational incentive to avoid taking sides leads the journalist to report special interests' claims to the voter. In equilibrium, the voter can remain uninformed even when the journalist is perfectly informed. Communication is improved if the journalist discloses her partisan leanings. The model provides an account of persistent public ignorance on climate change that is consistent with narrative and quantitative evidence.
\end{abstract}

Keywords: persuasion, global warming, strategic communication JEL: D83, D72, Q54

*I am grateful to Heski Bar-Isaac, Matthew Gentzkow, and Emir Kamenica for helpful conversations on related projects. I also thank Nava Ashraf, Renee Bowen, Sylvain Chassang, Jack Fanning, Elhanan Helpman, Fuhito Kojima, Navin Kartik, John Morgan, Andrei Shleifer, Dan Stone, David Strömberg, Linh Tô, Jan Zilinsky, the editor, Erzo Luttmer, four anonymous referees, numerous research assistants, seminar audiences at Brown University, the University of Chicago, Columbia University, Cornell University, Duke University, Harvard University, the University of Maryland, and the NBER, and especially NBER discussant Katia Zhuravskaya and Cornell discussant Steve Coate for comments. I acknowledge the support of the Alfred P. Sloan Foundation, the National Science Foundation, and the University of Chicago's Stigler Center for the Study of the Economy and the State. The Pew Research Center bears no responsibility for the analyses or interpretations of the data presented here. E-mail: jesse_shapiro_1@brown.edu. 


\section{Introduction}

The First Assessment Report of the Intergovernmental Panel on Climate Change (IPCC 1990) crystallized a scientific consensus that the climate is warming and that the cause is at least partly anthropogenic. The subsequent decade saw an explosion of activity by conservative think tanks and other organizations attempting to persuade the public that "the scientific evidence for global warming is highly uncertain" (McCright and Dunlap 2000). Much of this activity was directed at generating or influencing media coverage (Cushman 1998).

Skeptical perspectives on climate change have been prominent in the US news media. As recently as the early 2000s the majority of articles in national newspapers and segments in nightly news broadcasts about climate change were "balanced" in the sense of giving "roughly equal attention" to both sides (Boykoff and Boykoff 2004; Boykoff 2008). National newspapers in the 2000s mentioned the top five skeptical scientists about one-fourth as often as their mainstream counterparts (Grundmann and Scott 2014).

The news media are Americans' main source of climate-change information (Leiserowitz et al. 2010), so it is not surprising that Americans remain skeptical of the IPCC consensus, with only 52 percent reporting in 2010 that "most scientists believe that global warming is occurring" (Saad 2013). The US Senate did not ratify the Kyoto Protocol or the Waxman-Markey Bill, and the US performs poorly among rich countries in international ratings of carbon dioxide emissions and abatement (Hsu et al. 2014).

As I argue below, efforts by special interests to influence media coverage, and "balanced" reporting that creates the impression of controversy, are central elements of important policy debates ranging from climate change and secondhand smoke to the links between tobacco and cancer and between vaccines and autism. In this paper, I present a model that incorporates these elements. I use the model to understand when public policy is likely to reflect the best scientific information, and to study the effect of the institutional design of the news media on the quality of reporting.

In the model there is a binary state of the world on which a Bayesian voter has a neutral prior. There is a set of facts relevant to the state, which may be either ambiguous (facts exist to support both sides) or unambiguous (only one side is well supported by the evidence). There are two informed special interests, one representing each state. A journalist possesses the extant facts and may report all or some of them to the voter, who then chooses a policy to try to match the state.

Two frictions may interact to prevent the journalist from reporting the full set of facts to the voter. First, each special interest can pay a cost to present a claim to the journalist that, if reported to the voter, is indistinguishable from a fact. This assumption reflects the idea that the voter is not able to judge the 
underlying science; hence a claim that temperatures have always fluctuated throughout human history may carry as much weight with the voter as a claim that the atmospheric concentration of carbon dioxide is now at its highest level in 800,000 years.

The second friction is a reputational concern on the part of the journalist. With some probability the journalist is a captured type who tries to manipulate the voter's policy choice. The report of a captured type is not informative about the true state. A non-captured journalist therefore maximizes the market value of her future reports by minimizing the perception that she is captured.

Together, these two frictions create a bias towards reporting that the evidence is ambiguous even when it is not. A captured journalist makes an unambiguous report, so making an ambiguous report allows a non-captured journalist to signal her type to the voter. Special interests exploit this reputational incentive by providing the journalist with claims that run counter to the truth, thus allowing the journalist to report both sides of the issue even when the underlying science favors only one side.

The model generates novel predictions about when special interests' activities distort public policy. As in canonical models of special interests (e.g., Grossman and Helpman 1996), equilibrium policies are farther from the ideal the more motivated and effective are the special interests. More surprisingly, the gap between the equilibrium policy and the ideal policy is wider the greater is the likelihood that the facts are unambiguous, because special interests have an especially strong incentive to manufacture counter-claims in the face of unambiguous evidence.

The model also has implications for the design of journalistic institutions. Informative communication is partially restored by allowing the journalist to disclose her partisan leanings—say, her voting record or party affiliation. The reason is simple: a journalist with a convincing track record of Republican votes who reports unambiguously that climate change is real is unlikely to be thought captured by Greenpeace or the Sierra Club. Interestingly, many ethical guidelines for journalists explicitly advise against or prohibit disclosure of personal political leanings (e.g., New York Times 2004a; Reporters Without Borders 2014). In the model, such prohibitions can make reporting less informative. I also show that requiring "fair" reporting, as many countries do of their broadcasters, can be counterproductive in the presence of special interests.

Extensions to the baseline model yield additional implications for special interests' influence on policy. When the voter's prior favors one state over another, the more active special interest group is the one aligned with the favored state, and the voter never gets a report that fully contradicts that state. In this sense, special interests' incentives drive a form of "pandering," i.e., reports favoring the voter's prior. When special interests instead differ in their ability to manufacture evidence, the voter is better able to learn the state opposed by the weaker interest group. When the issue at hand is "apolitical," in the sense that capture is 
unlikely, policy distortion vanishes, as it does when the journalist wishes to mimic an accurate type.

The paper also develops an extension in which the reporting language is not constrained by the set of available facts. In a model with a general discrete signal and message space, reputational concerns lead to an endogenous limit on the amount of information that the journalist can communicate in equilibrium. The reason is that a captured journalist wants to make a very informative report, which means that a journalist wishing to appear neutral avoids conveying a lot of information to the voter. This analysis shows that a concern for appearing neutral constrains the amount of information that a journalist can convey, outside of the particular communication structure assumed in the baseline model.

An empirical section argues that evidence from climate change and other issues is consistent with an important role for special interests and the media in determining public opinion and public policy. Differences in the public response to ozone depletion and global warming line up with differences in special interests' incentives. There is a surprisingly weak relationship between news media consumption and belief in global warming, but a very strong relationship between news media consumption and knowledge of uncontroversial facts. Public acceptance of climate change is greater in countries whose news media do not report skeptics' claims, and this relationship cannot be easily explained by reverse causality from beliefs to media coverage. These pieces of evidence are consistent with the setup and implications of the model.

A final section of the paper considers alternative explanations of the evidence, such as voters' ideological predispositions, the entertainment value of controversy, and journalists' uncertainty about the evidence. These forces are important, but on their own they fail to account for important facets of media coverage on issues like climate change. I stress, however, that the evidence I present is only suggestive in nature, and that the model I propose also fails to account for some aspects of the evidence.

An especially important caveat to the applicability of the baseline model is that, for a large range of parameters, the voter learns nothing in equilibrium. This clearly goes too far: Americans will eventually accept anthropogenic climate change just as they did the smoking-cancer link or the health effects of childhood lead exposure. The goal of the model is not to argue that such learning is impossible but to highlight some important forces that slow it down. In this respect, an important limitation of the static model in this paper is that it does not address how beliefs on a given issue evolve over time.

The paper makes three main contributions. First, the paper contributes a model of special interest competition via profit-driven media in which media institutions and voter beliefs are modeled explicitly. ${ }^{1}$ In

\footnotetext{
${ }^{1}$ Classical economic models of special interests' influence on public policy treat the expenditure of resources to influence voter beliefs and information implicitly, either as part of a reduced-form function relating expenditures to votes or influence or as a motivation for politicians to seek campaign resources from interest groups (e.g., Stigler 1971; Peltzman 1976; Becker 1983; Grossman and Helpman 1994). Another class of models treats lobbying as a form of strategic information transmission from interest groups to legislators (e.g., Austen-Smith and Wright 1992; Bennedsen and Feldmann 2002).
} 

no explicit signal structure or model of media institutions. ${ }^{2}$ Sobbrio (2011) adds an explicit model of the media, but models media as policy-motivated. Stone (2011) models interest groups' strategic choice of both research and lobbying activity, but in a model without a media actor. Accounting simultaneously for the news media's reputational concerns and for special interests' policy motivations is crucial for the model's policy implications, and for its testable predictions.

Second, the paper contributes a novel economic account of the causes and effects of objectivity in journalism. The norm of objectivity has been the focus of extensive study by sociologists of journalism (Tuchman 1972; Schudson 2001) but to my knowledge no formal model exists to explain or study it. The model explains objectivity as a kind of political correctness in the sense of Morris (2001). However, unlike in Morris (2001), because there are partisans on both sides of the issue, political correctness creates a bias towards uninformative, neutral reports rather than reports that favor a "politically correct" position. I show that this bias towards uninformative reports persists even when the journalist has access to a rich message space. $^{3}$

Third, this paper contributes to the broader literature on strategic communication with reputational concerns (e.g., Morris 2001; Ely and Välimäki 2003; Gentzkow and Shapiro 2006; Ottaviani and Sørensen 2006) by allowing that reputational concerns on the part of the sender (journalist) are exploited by a third party (special interest) in order to manipulate the actions of the receiver (voter). As in Leaver (2009), accounting for these interactions generates novel insights and comparative statics. For example, it is because of special interests that the voter does not benefit from an improvement in the journalist's information. And when the voter has a non-neutral prior, it is the actions of special interests, rather than pandering by the journalist as in Gentzkow and Shapiro (2006), that ensure that the prior is not contradicted in equilibrium. ${ }^{4}$

Although the model is abstract enough to apply to many topics, I motivate many details with the case of climate change. The paper thus contributes to a large literature, mostly outside of economics, on the communication of scientific findings to the public (Mazur 1973; Check 1987; Limoges 1993; Dearing 1995; Boykoff and Boykoff 2004), and on the role of expert communities in environmental policy (Haas 1989, 2000; Toke 1999). ${ }^{5}$

\footnotetext{
${ }^{2}$ Strömberg (2001) studies lobbying by opposing groups of voters when media provide information about candidate platforms. Petrova (2012) and Germano and Meier (2013) study the effect of advertising profits on media bias with direct (Petrova 2012) or indirect (Germano and Meier 2013) incentives to provide favorable coverage to special interests.

${ }^{3}$ The assumption that interest groups may make claims that the voter cannot distinguish from fact degrades the benefit from advocacy highlighted in Dewatripont and Tirole (1999).

${ }^{4}$ The paper's analysis of the effect of disclosing the journalist's partisan leanings relates to a broader literature on disclosure of conflicts of interest (e.g., Li and Madarász 2008).

${ }^{5}$ Most formal models of policy expertise focus on agency frictions that arise when policymaking is delegated to an informed actor such as a bureaucrat or committee (e.g., Gilligan and Krehbiel 1987; Callander 2008).
} 
The remainder of the paper is organized as follows. Section 2 motivates the model with a discussion of case evidence. Section 3 defines the baseline model. Section 4 characterizes its equilibrium. Section 5 develops implications for the design of media institutions. Section 6 develops some extensions and generalizations of the model. Section 7 presents additional evidence on the role of special interests and the media in climate change and other issues. Section 8 discusses alternative explanations for the evidence. Section 9 concludes. Appendix A addresses the robustness of the model's implications to changes in the model structure.

\section{Background and Motivation}

The two frictions at the heart of the model are influence activities by special interests and reputational concerns on the part of journalists. In this section, I motivate each of these in turn using case evidence from climate change and other issues.

\subsection{Special Interests' Efforts to Influence the News}

Special interests who wish to affect public perception of a scientific issue routinely undertake organized efforts to influence media reporting.

A good illustration of special interest tactics comes from a leaked 1998 memo by a public relations representative of the American Petroleum Institute. The memo outlines a "Global Climate Science Communications Plan." The plan would fund development of a "global climate science information kit for media including peer-reviewed papers that undercut the 'conventional wisdom' on climate science." This "information kit" would "present scientific uncertainties in language that the media and public can understand." The plan would also "identify, recruit, and train a team of five independent scientists to participate in media outreach" and "conduct briefings by media-trained scientists for science writers in the top 20 media markets." Metrics of success include "the percent of media articles that raise questions about climate science" and "total audience exposed to newspaper, radio, [and] television coverage of science uncertainties" (Walker 1998; see also Cushman 1998).

Other special interests have used similar tactics (Oreskes and Conway 2010). For example, in 1988, in the face of rising concern over the health effects of secondhand smoke, an industry working group proposed funding seven research projects that would "be available for publication in scientific literature and popular press over the next three years" (Environmental Tobacco Smoke Working Group 1988; Drope and Chapman 2001). The Tobacco Institute assembled a group of affiliated experts, including 14 academics, who were 

responding to media reports by preparing critiques of adverse research" (Tobacco Institute Undated; Drope and Chapman 2001).

That special interests spend resources to influence media coverage is good economic evidence that such efforts can be fruitful. Further evidence comes from examining media coverage directly.

Media coverage of climate change remained "balanced" long after the scientific consensus had crystallized. Boykoff (2008) finds that from 1995 to 2004, 69 percent of US television news broadcasts on anthropogenic climate change "provided roughly equal attention and emphasis to competing viewpoints." Boykoff and Boykoff (2004) report similar findings for print media. Advocates for skeptical positions are routinely cited in the news even though nearly all active climate researchers accept the core tenets of the IPCC consensus (Oreskes 2004; Doran and Zimmerman 2009; Anderegg et al. 2010). From 2000 to 2010, the two most prominent skeptical scientists were cited in the top 10 US newspapers 31 percent as often as the most-cited scientific advocate for anthropogenic climate change (Grundmann and Scott 2014). As recently as 2009-10, 34 percent of climate-change articles in the New York Times or Wall Street Journal included a skeptical voice on climate change (Painter and Ashe 2012).

Balanced media coverage will create public doubt only if citizens cannot easily tell which scientific claims are accurate, as seems likely in the case of climate change. There is no randomized controlled trial to demonstrate that human activity is warming the earth. The conclusion comes instead from a mix of basic theory, climate modeling, and direct measurement, all of which require significant expertise to understand. In reaction to the IPCC report, the Nongovernmental International Panel on Climate Change (NIPCC) issued its own assessment report arguing that "natural causes are very likely to be the dominant cause" of any climate change (Idso and Singer 2009). This document is 868 pages long and is filled with technical language and data plots. It is hard to see how a lay reader could evaluate its claims directly. Nor is it easy to dismiss the report's authors for being "biased": the NIPCC implies, to the contrary, that the IPCC is biased because it represents governments who wish to intervene in the economy. ${ }^{6}$

As with claims of fact, it is likewise difficult to see how citizens could tell which credentialed advocates speak for the scientific consensus and which speak for a vocal minority. The two most cited scientific skeptics in the US press from 2000 to 2010 (Grundmann and Scott 2014) were, respectively, an atmospheric physicist who served as the first director of the US Satellite Weather Service, and a solid-state physicist who served as president of the National Academy of Sciences. Press mentions of these credentialed skeptics

\footnotetext{
${ }^{6}$ The NIPCC states that "Because we do not work for any governments, we are not biased toward the assumption that greater government activity is necessary" (NIPCC 2011).
} 
naturally create an impression of ongoing scientific controversy. ${ }^{7}$

\subsection{Journalists' Reputational Concerns}

Modern Anglo-American journalists routinely strive to give "airtime" to both sides of an issue (Tuchman 1972 ) in order to "express fairly the position of each side" (Donsbach and Klett 1993). This practice is often codified in ethical guidelines. ${ }^{8}$

In the model, the journalist makes balanced reports to avoid seeming to favor one side of an issue, and hence to maintain credibility on future issues. Sociological accounts are consistent with this mechanism. The modern ideal of objectivity arose in the 1920s, partly as a means for journalists to "assert their collective integrity" in the face of "public relations specialists" and other "information mercenaries" attempting to influence the press (Schudson 2001). Journalists often report claims they cannot verify directly, and quoting someone critical (or likely to be critical) of a given claim provides a routine way to avoid appearing to endorse the original claim (Tuchman 1972). ${ }^{9}$ Consistent with this interpretation, laboratory evidence shows that readers regard a news organization as more credible when the organization's article reports both sides of a controversy (Fico et al. 2004).

Reputational accounts of the origins of objectivity are also consistent with the backlash that news outlets face when one-sided reporting proves inaccurate. For example, the New York Times lost face over its reporting on the presence of weapons of mass destruction in Iraq when subsequent events revealed that quoted sources exaggerated the case for the presence of such weapons (Okrent 2004; New York Times 2004b). This episode was especially costly because of the appearance that the Times had tilted its reporting in order to retain access to administration sources (Foer 2004).

Perhaps because of the fear of reputational harm, the editorial commitment to balance often goes surprisingly far. For example, it was not until 1979 that the New York Times stopped routinely quoting Tobacco Institute representatives to provide the "other side" of the smoking-cancer link (Hoyt 2008). It seems hard to

\footnotetext{
${ }^{7}$ Consider citations to Fred Singer, a prominent skeptic and a lead co-author of the NIPCC assessment report. A Los Angeles Times article in 1998 that cited Singer was titled "1997 ranks as warmest year of the century. New figures raise concerns about risks of global heating. Some remain skeptical of phenomenon" (Gerstenzang 1998). Singer was similarly cited in a New York Times article about a new geological study attributing global warming to human activity (Revkin 2000), and a Philadelphia Inquirer article about evidence that recent climatic changes are very unusual in long-term perspective (Toner 2006).

${ }^{8}$ For example, the Code of Ethics of the Radio Television Digital News Association (RTDNA) calls upon journalists to "present a diversity of expressions, opinions, and ideas in context" (RTDNA 2013).

${ }^{9}$ Tuchman's (1972) seminal sociological account of objectivity in the newsroom offers the following abstract example. "A [Democratic] US senator may claim that America lags behind the Soviet Union in the development of a specific type of missile. A reporter certainly cannot check that claim in time to meet his deadline, and it is possible he could never locate adequate information with which to assess the extent to which the claim is a 'fact'... He can, however, write that the [Republican] secretary of defense stated [the charge is 'false'] ... Presenting both truth-claim ' $A$ ' attributed to the senator and truth-claim ' $B$ ' attributed to the secretary of defense, the newsman may then claim he is 'objective' because he has presented 'both sides of the story' without favoring either man or political party."
} 

quoting industry representatives allowed the newspaper to avoid the appearance of favoring anti-smoking policies in its news reporting.

\section{Model}

The game proceeds in two identical periods. I begin by describing the first period in detail, omitting time subscripts for brevity. I then describe how the elements of the model are related across periods. After completing the description of the model, I define the solution concept and measures of equilibrium policy distortion.

\subsection{First Period}

There is a binary state of the world $\omega \in\{l, r\}$ with $\operatorname{Pr}(\omega=r)=\frac{1}{2}$. A journalist sends a message $m$ to a voter who does not know $\omega$ and who chooses a policy $a \in[0,1]$ after observing $m$. Each of two interested parties, denoted $l$ and $r$, then receives a payoff that depends on the voter's policy choice. Section 6 extends the analysis to the case in which $\operatorname{Pr}(\omega=r) \neq \frac{1}{2}$ and to the case in which there is only a single interested party.

There is a body of scientific evidence about the state. Denote by $\sigma$ the set of extant facts, with $\sigma \subseteq\{l, r\}$ and $\sigma \neq \emptyset$. When $\sigma=l$ or $\sigma=r$ I will say that the evidence is unambiguous; otherwise I will say that it is ambiguous. ${ }^{10}$ If the evidence is ambiguous then it is uninformative in the sense that $\operatorname{Pr}(\omega=r \mid \sigma=\{l, r\})=\frac{1}{2}$. If the evidence is unambiguous it is fully informative in the sense that $\operatorname{Pr}(\omega=r \mid \sigma=r)=\operatorname{Pr}(\omega=l \mid \sigma=l)=1$. Although I will speak of $\sigma$ as a collection of facts, we may also think of it as a summary of expert opinion, with unambiguous evidence corresponding to an expert consensus and ambiguous evidence corresponding to divided experts.

The probability of unambiguous evidence is $\gamma \in(0,1)$ independently of $\omega$. The parameter $\gamma$ measures the quality of the information available on the topic. We may also think of $\gamma$ as a measure of the amenability of the topic to empirical science: when $\gamma$ is low, data are likely to be indecisive. The parameter $\gamma$ is common knowledge: the voter does not directly observe the realization of $\sigma$ but does know the ex ante likelihood that $\sigma$ is a singleton. That is, the voter can tell whether an issue is likely to be more (e.g., trends in global carbon dioxide levels) or less (e.g., existence of extraterrestrial life) amenable to empirical science.

\footnotetext{
${ }^{10}$ Formally the statement should be for $\sigma=\{l\}$ or $\sigma=\{r\}$; here and throughout I omit set notation for singleton sets when doing so does not make the notation unclear.
} 

the party's position. The cost $k$ is common knowledge. As party $j$ only acts if $j \notin \sigma$, it is implicit that the parties are informed of $\sigma$. This assumption is reasonable in light of narrative evidence that, for example, tobacco industry representatives reviewed scientists' research extensively when developing their outreach strategy (Michaels 2008). Let $j^{*} \in\{\emptyset, l, r\}$ denote the identity of the party that has made a claim, with $j^{*}=\emptyset$ denoting that no party has done so.

The journalist learns the facts $\sigma$. In practice learning $\sigma$ requires effort; here I ignore the costs of investigation to focus on the journalist's reporting incentives. This follows Morris (2001) and Gentzkow and Shapiro (2006).

The journalist has a leaning $\lambda \in\{l, r\}$ which is equally likely to be $l$ or $r$. This leaning reflects the journalist's own policy preference or worldview and is the journalist's private information.

The journalist has a type $\tau \in\{s, h, c\}$ with commonly known probability $\eta_{\tau^{\prime}} \in(0,1)$ of a given type $\tau^{\prime}$ and $\eta_{s}+\eta_{h}+\eta_{c}=1$. Type $s$ is a strategic type who may send any nonempty message $m \subseteq\left(\sigma \cup j^{*}\right)$. Type $h$ is an honest type who reports $m=\sigma$. Type $c$ is a captured type who reports $m=\lambda$. Although the captured type is non-strategic, in the unique equilibrium characterized in section 4 , a captured type inheriting the payoff of party $\lambda$ would prefer to report $m=\lambda$. We may therefore think heuristically of the captured type as a type that shares the interests of one of the parties. We may also think of the captured type as possessing an ideological commitment to one side of the issue.

The journalist's type is unknown to the voter. To simplify exposition I assume that the parties know the journalist's type. Appendix A shows that key welfare statements are preserved if instead the parties do not know the journalist's type. Appendix A also shows that key welfare statements are preserved in a model variant in which the captured type cannot fabricate evidence and so must make a report in $\sigma \cup j^{*}$. Section 6.3 presents a model with a more general message space, a captured type that acts strategically, and no interested parties.

After the journalist sends the message $m$, the voter chooses the policy $a \in[0,1]$ and learns the true state $\omega$, suffering a loss given by

$$
L(a, \omega)= \begin{cases}a^{2} & \omega=l \\ (1-a)^{2} & \omega=r .\end{cases}
$$

Party $r$ then receives payoff $v a$ and party $l$ receives payoff $v(1-a)$, where $v>0$ is a commonly known parameter that denotes the policy's economic importance. (These payoffs are gross of the claim cost $k$.) 

eventually climate change is sufficiently severe as to be obvious to the voter. The characterization in section 4 would not change if instead the voter only learned $\omega$ (and her payoff) at the end of the game.

At the beginning of the period, the voter makes a payment $\pi$ to the journalist equal to the expected value of receiving the journalist's report. We can write this payment as $\pi=\frac{1}{4}-\mathrm{E}(L(a, \omega))$, where $\frac{1}{4}$ is the voter's expected loss if she receives no report, and where the expectation is taken with respect to the joint distribution of $a$ and $\omega$. As the first-period payment is sunk, it does not affect the journalist's incentives, but the prospect of an analogous payment in the second period will influence the journalist's equilibrium behavior.

We may think of the payment $\pi$ as reflecting the outcome of a market process. For example, $\pi$ would be the profit-maximizing price for a monopoly news outlet. Appendix A shows that the baseline model's predictions extend to a variant in which many news outlets compete for readership.

To recap, the timing of the first period is as follows. (i) The voter pays the journalist an amount $\pi$ equal to the expected value of the journalist's report. (ii) Nature draws the state $\omega$, the facts $\sigma$, and the journalist's type and leaning. (iii) The parties learn the facts $\sigma$ and the journalist's type, and party $j \notin \sigma$ decides whether to pay the cost $k$ to make a claim supporting its position. (iv) The journalist learns her type and leaning, the facts $\sigma$, and the identity $j^{*}$ of the party that has made a claim, and chooses her report $m$. (v) The voter learns the journalist's report $m$ and chooses her action $a$. (vi) The voter learns the state $\omega$, realizes loss $L(a, \omega)$, and updates her beliefs $\hat{\eta}_{\tau}(m, \omega)$ about the journalist's type.

\subsection{Second Period}

The second period is just like the first. The state of the world and the journalist's leaning are drawn independently across periods, but the journalist's type persists. The interested parties are short-run players and the voter and journalist are long-run players. These assumptions reflect the idea that over time the same journalist reports to the citizenry on different policy issues (e.g., climate change, nuclear energy) with different stakeholders. The long-run players do not time-discount their payoffs. Thus, the voter's payoff is (inverse to) the sum of her losses across the two periods, and the journalist's payoff is the sum of the payments $\pi$ across the two periods. Appendix A shows that key welfare properties of the equilibrium of the baseline two-period game hold for an equilibrium of a game with an arbitrary finite number of periods. 


\subsection{Solution Concept}

The solution concept is Perfect Bayesian Equilibrium. Because the strategic journalist is indifferent over all possible reports in the second period, I adopt the refinement that the strategic journalist reports $m=$ $\sigma$ whenever indifferent. As a microfoundation, we may imagine that the journalist has a lexicographic preference for honesty as in Demichelis and Weibull (2008) or Kartik et al. (2014); see also Kartik (2009). Except where stated, I use the term equilibrium to refer to Perfect Bayesian Equilibrium with this refinement.

\subsection{Measures of Equilibrium Policy Distortion}

Let the policy distortion $\Phi$ in some equilibrium in some period be given by $\Phi \equiv \mathrm{E}(L(a, \omega))-\mathrm{E}(L(\tilde{a}, \omega))$, where $\tilde{a}$ is the random variable describing the voter's optimal action if it is common knowledge that the strategic journalist reports honestly $(m=\sigma) .{ }^{11}$ The policy distortion measures the distance, in units of the voter's expected payoff, between equilibrium policies and ideal policies. It is easy to show that $\Phi \in\left[0, \frac{1}{4} \gamma\right]$.

Define the strategic distortion as $\Phi_{0} \equiv \lim _{\eta_{h} \rightarrow 0} \lim _{\eta_{c} \rightarrow 0} \Phi$, if this limit exists. The strategic distortion is the extent of the policy distortion when non-strategic types become rare. If $\Phi_{0}=\frac{1}{4} \gamma$ the voter is uninformed in this limit; if $\Phi_{0}=0$ then the voter learns $\sigma$.

When not otherwise specified, the terms policy distortion and strategic distortion refer to the first period.

\section{Characterization of Equilibrium}

Begin with the second period. As the voter's payment to the journalist is sunk at the time of the report, in any equilibrium the strategic type reports $m=\sigma$, and the interested parties do not claim.

The payment to the journalist at the beginning of the second period may depend on the outcome of the first period only through the voter's beliefs $\hat{\eta}_{\tau}(m, \omega)$ about the journalist's type. Because the captured type's report is uninformative, the payment is strictly decreasing in $\hat{\eta}_{c}(m, \omega)$. Because the honest and strategic types make the same report in the second period, the payment does not depend on $\hat{\eta}_{h}(m, \omega)$.

In the first period, it is a dominant strategy for the strategic journalist to report $m=\{l, r\}$ whenever $\{l, r\} \subseteq\left(\sigma \cup j^{*}\right)$ because $\hat{\eta}_{c}(\{l, r\}, \omega)=0$ and $\hat{\eta}_{c}(l, \omega), \hat{\eta}_{c}(r, \omega)>0$ for each $\omega$.

Because of the quadratic form of the voter's loss function, the voter's optimal action $a$ given message $m$ is $a(m)=\operatorname{Pr}(\omega=r \mid m)$. For any proposed strategies by the parties, all possible messages $m$ occur on the equilibrium path with positive probability, so $\operatorname{Pr}(\omega=r \mid m)$ is governed by Bayes' Rule.

\footnotetext{
${ }^{11}$ Expectations are taken with respect to the joint distributions of $(a, \omega)$ and $(\tilde{a}, \omega)$, respectively.
} 
What remains is to characterize the equilibrium strategies of the parties in the first period. Claiming does not influence the reports of non-strategic types, so the party will claim only if the journalist is strategic. Strategies of the parties are thus fully characterized by $\rho_{l}$ and $\rho_{r}$, where $\rho_{j}$ is the probability that party $j$ makes a claim if $j \notin \sigma$ and the journalist is strategic.

Party $j$ is willing to make a claim if and only if

$$
\Delta\left(\rho_{j}, \rho_{\sim j}\right) \equiv \operatorname{Pr}(\omega=j \mid m=\{l, r\})-\operatorname{Pr}(\omega=j \mid m=\sim j) \geq \frac{k}{v}
$$

where $\sim j$ indexes the party other than $j$, and recall that $k / v$ is the relative cost of claiming.

The benefit $\Delta\left(\rho_{j}, \rho_{\sim j}\right)$ to claiming for party $j$ depends on the strategies $\left(\rho_{j}, \rho_{\sim j}\right)$ through the voter's beliefs. The possibility of both captured and honest journalists ensures that all messages occur with strictly positive probability regardless of the strategies $\left(\rho_{j}, \rho_{\sim j}\right)$. Voters' beliefs are therefore governed by Bayes' Rule:

$$
\begin{aligned}
\operatorname{Pr}(\omega=j \mid m=\sim j) & =\frac{\frac{1}{2} \eta_{c}}{\frac{1}{2} \eta_{c}+\left(\frac{1}{2} \eta_{c}+\eta_{h} \gamma+\eta_{s} \gamma\left(1-\rho_{j}\right)\right)} \\
\operatorname{Pr}(\omega=j \mid m=\{l, r\}) & =\frac{1}{2} \frac{\eta_{h}(1-\gamma)+\eta_{s}\left((1-\gamma)+\gamma \rho_{\sim j}\right)}{\eta_{h}(1-\gamma)+\eta_{s}\left((1-\gamma)+\gamma\left(\frac{1}{2} \rho_{\sim j}+\frac{1}{2} \rho_{j}\right)\right)} .
\end{aligned}
$$

Any equilibrium is symmetric in the sense that $\rho_{l}=\rho_{r}=\rho$ for some $\rho \in[0,1]$. To see this, observe that from equations (2) and (3) it follows that

$$
\operatorname{sgn}\left(\Delta\left(\rho_{\sim j}, \rho_{j}\right)-\Delta\left(\rho_{j}, \rho_{\sim j}\right)\right)=\operatorname{sgn}\left(\rho_{j}-\rho_{\sim j}\right),
$$

from which (i) if $\rho_{j} \in(0,1)$ for all $j$ then $\rho_{l}=\rho_{r}$, (ii) if $\rho_{j}=1$ then $\rho_{\sim j}=1$, and (iii) if $\rho_{j}=0$ then $\rho_{\sim j}=0$.

There is a unique equilibrium probability of claiming $\rho^{*}$. This follows from the fact that $\Delta(\rho) \equiv \Delta(\rho, \rho)$ is strictly decreasing in $\rho$, because the greater is the probability of claiming, the more likely is an unambiguous report to come from a captured journalist. ${ }^{12}$ If $\Delta(0) \leq \frac{k}{v}$ then $\rho^{*}=0$. If $\Delta(1) \geq \frac{k}{v}$ then $\rho^{*}=1$. If $\Delta(0)>\frac{k}{v}>\Delta(1)$ then $\rho^{*} \in(0,1)$ solves $\Delta\left(\rho^{*}\right)=\frac{k}{v}$. The strictly mixing equilibrium in this last case reflects a balance between voters' beliefs and parties' strategies: a greater probability of claiming would lower the credibility of an unambiguous report and thus reduce the incentive to claim, and a lower probability of

\footnotetext{
${ }^{12}$ Symmetry implies that $\operatorname{Pr}(\omega=j \mid m=\{l, r\})=\frac{1}{2}$ so that $\Delta(\rho)=\frac{1}{2} \frac{\eta_{h} \gamma+\eta_{s} \gamma(1-\rho)}{\eta_{c}+\eta_{h} \gamma+\eta_{s} \gamma(1-\rho)}$.
} 
claiming would do the opposite.

The following proposition collects the preceding results.

Proposition 1. There is a unique equilibrium with the following strategies. In the second period, the strategic journalist reports $m=\sigma$ and the parties do not claim. In the first period, the strategic journalist reports $m=\{l, r\}$ whenever $\{l, r\} \subseteq\left(\sigma \cup j^{*}\right)$ and $m=\sigma$ otherwise, and the parties claim with probability $\rho^{*}$, with $\rho^{*}=0$ if $\Delta(0) \leq \frac{k}{v}, \rho^{*}=1$ if $\Delta(1) \geq \frac{k}{v}$, and $\rho^{*} \in(0,1)$ solving $\Delta\left(\rho^{*}\right)=\frac{k}{v}$ otherwise. In both periods the voter chooses a $(m)=\operatorname{Pr}(\omega=r \mid m)$ according to Bayes' Rule.

Now we can characterize the policy distortion. In the second period there is no policy distortion. In the first period the voter's equilibrium expected loss is given by

$$
\mathrm{E}(L(a(m), \omega))=\operatorname{Pr}(m=\{l, r\}) \frac{1}{4}+(1-\operatorname{Pr}(m=\{l, r\})) \operatorname{Pr}(\omega=r \mid m=l)(1-\operatorname{Pr}(\omega=r \mid m=l)) .
$$

Intuitively, if $m=\{l, r\}$ then the voter learns nothing, and if $m=l$ then the event that $\omega=r$ is Bernoulli with variance $\operatorname{Pr}(\omega=r \mid m=l)(1-\operatorname{Pr}(\omega=r \mid m=l))$.

The voter's expected loss $\mathrm{E}(L(a(m), \omega))$ is strictly decreasing in $\frac{k}{v}$ in an interior equilibrium. Note first that $\operatorname{Pr}(\omega=r \mid m=l) \in\left(0, \frac{1}{2}\right)$ and $\operatorname{Pr}(m=\{l, r\}) \in(0,1)$. Next, recall that $\Delta(\rho)$ is strictly decreasing in $\rho$, so that the equilibrium condition $\Delta\left(\rho^{*}\right)=\frac{k}{v}$ implies that both $\operatorname{Pr}(\omega=r \mid m=l)$ and $\operatorname{Pr}(m=\{l, r\})$ are strictly decreasing in $\frac{k}{v}$.

The voter's expected loss does not depend on $\gamma$ in an interior equilibrium. By symmetry, $\operatorname{Pr}(\omega=r \mid m=\{l, r\})=$ $\frac{1}{2}$, so by equation (2) the equilibrium condition $\Delta\left(\rho^{*}\right)=\frac{k}{v}$ implies that $\operatorname{Pr}(\omega=r \mid m=l)$ does not depend on $\gamma$. Symmetry and equation (3) then imply that $\operatorname{Pr}(m=\{l, r\})$ does not depend on $\gamma \cdot{ }^{13}$

Recall that the policy distortion is the difference between the voter's expected loss in equilibrium and her expected loss if the strategic journalist reports honestly. Because the voter's expected loss in the latter case does not depend on $\frac{k}{v}$ and is strictly decreasing in $\gamma$, we have the following comparative statics:

Proposition 2. In an interior equilibrium, i.e., if $\Delta(0)>\frac{k}{v}>\Delta(1)$, the policy distortion $\Phi$ is strictly decreasing in the relative cost of claiming $\frac{k}{v}$ and strictly increasing in the probability $\gamma$ that the facts are unambiguous.

\footnotetext{
${ }^{13}$ To derive the voter's expected loss, note that from equation (2), in an interior equilibrium $\operatorname{Pr}(\omega=r \mid m=l)=\frac{1}{2}-\frac{k}{v}$. From equation (3) and the fact that $1-\operatorname{Pr}(m=\{l, r\})=2 \operatorname{Pr}(m=l)$ by symmetry, $(1-\operatorname{Pr}(m=\{l, r\})) \operatorname{Pr}(\omega=r \mid m=l)=\frac{1}{2} \eta_{c}$. Then from equation (5),

$$
\mathrm{E}(L(a(m), \omega))=\frac{1}{4}\left(1-\frac{2 \eta_{c}}{\frac{v}{k}\left(\frac{1}{2} \frac{v}{k}-1\right)}\right) .
$$
}


The economics of proposition 2 are as follows. In an interior equilibrium the parties are indifferent to claiming. The incentive to claim $\Delta\left(\rho^{*}\right)$ is tightly linked to the informativeness of the equilibrium, because it is the effect on the voter's posterior of receiving an ambiguous message rather than an unambiguous one. As $\frac{k}{v}$ rises, so does the equilibrium $\Delta\left(\rho^{*}\right)$, and the voter is better off ( $\rho^{*}$ falls). As $\gamma$ rises, the equilibrium $\Delta\left(\rho^{*}\right)$ remains unchanged, and the voter is no better off ( $\rho^{*}$ rises just enough to offset the increase in $\gamma$ ). Note that these same comparative statics hold, at least weakly, when we do not restrict attention to an interior equilibrium. ${ }^{14}$

In the limit as non-strategic types become rare, the policy distortion has a very simple form. To see this note first that if $\frac{k}{v} \geq \frac{1}{2}$ then $\rho^{*}=0$ because $\frac{1}{2}>\Delta(0)$. Next suppose that $\frac{k}{v}<\frac{1}{2}$. Pick some $\eta_{h}>0$. Because $\Delta(1)$ is strictly decreasing in $\eta_{c}$ and $\lim _{\eta_{c} \rightarrow 0} \Delta(1)=\frac{1}{2}$, there exists some $\bar{\eta}_{c}\left(\eta_{h}\right)>0$ such that $\rho^{*}=1$ for all $\eta_{c}<\bar{\eta}_{c}\left(\eta_{h}\right)$. It follows that $\lim _{\eta_{h} \rightarrow 0} \lim _{\eta_{c} \rightarrow 0} \mathrm{E}(L(a(m), \omega))=\frac{1}{4}$ :

Proposition 3. In the limit as non-strategic types become rare, the voter is uninformed if $\frac{k}{v}<\frac{1}{2}$ and is fully informed of the facts $\sigma$ otherwise. That is, the strategic distortion $\Phi_{0}$ is equal to $\frac{1}{4} \gamma$ if $\frac{k}{v}<\frac{1}{2}$ and 0 otherwise.

An intuition is as follows. If and only if $\frac{k}{v} \leq \frac{1}{2}$, a party would pay $k$ to get policy $\frac{1}{2}$ instead of her least preferred policy. When $\eta_{c}$ is small, the parties face almost exactly this choice, because unambiguous reports reveal the true state with near certainty, and ambiguous reports reveal nothing. Therefore when $\frac{k}{v}<\frac{1}{2}$ the parties claim, and when $\frac{k}{v} \geq \frac{1}{2}$ they do not. Observe that reversing the order of limits would change this intuition, because when $\eta_{h}$ gets small relative to $\eta_{c}$, even unambiguous reports can be uninformative in the limit. Proposition 3 therefore approximates a world in which most journalists are strategic and most unambiguous reports are truthful.

The finding in propositions 2 and 3 that better exogenous information $\gamma$ increases the policy distortion shows the value of explicitly modeling the communication between the journalist and the voter. The finding comes about because the parties' incentive to claim is linked to the informativeness of reports: the more the voter learns from an unambiguous report, the more the parties wish to prevent such a report from contradicting their interests. A countervailing force would arise if special interests faced a higher cost $k$ of manufacturing evidence for issues with a high $\gamma$. But skeptics' success in contesting even basic facts like the trend in global temperatures suggests that, even in cases where $\gamma$ is high, $k$ is sufficiently low to permit substantial special-interest activity.

\footnotetext{
${ }^{14}$ If $\rho^{*}=0$ then the policy distortion is 0 . If $\rho^{*}=1$ then it is obvious that the policy distortion does not depend on $\frac{k}{v}$ and it is straightforward to show that the policy distortion is strictly increasing in $\gamma$.
} 


\section{Implications for Private and Public Policy}

\subsection{Disclosure of Journalist's Leaning}

If the journalist can credibly disclose her partisan leaning, say by publicizing her party affiliation or making visible endorsements, then the strategic journalist can communicate more information in equilibrium.

To illustrate, suppose without loss of generality that it is common knowledge that $\lambda=r$. Then, as in section 4, the journalist's payoff at the beginning of the second period is a strictly decreasing function of $\hat{\eta}_{c}(m, \omega)$ that does not depend on $\hat{\eta}_{h}(m, \omega)$. But the implications for the strategic journalist's firstperiod play are now very different, because $\hat{\eta}_{c}(l, l)=0$, with $\hat{\eta}_{c}(\{l, r\}, \omega)=0$ and $\hat{\eta}_{c}(r, \omega)>0$ for all $\omega$. Therefore the strategic journalist reports $m=\sigma$ when $\sigma=l$, and $m=\sigma \cup j^{*}$ otherwise. (Recall that $j^{*}$ denotes the identity of the party that has made a claim, if any.)

It follows that party $r$ never claims. Arguments analogous to those in section 4 establish that there is a unique probability $\rho_{l}^{*}$ with which party $l$ claims in equilibrium. ${ }^{15}$ Continuity implies that the voter's loss attains a limit as non-strategic types become rare. ${ }^{16}$ And because $\lim _{\eta_{h} \rightarrow 0} \lim _{\eta_{c} \rightarrow 0} \operatorname{Pr}(m=l)=\frac{1}{2} \gamma$ and $\operatorname{Pr}(\omega=l \mid m=l)=1$, the voter's loss is bounded away from $\frac{1}{4}$ in the limit:

Proposition 4. If it is common knowledge that the journalist's leaning is $\lambda=r$, then in the limit as nonstrategic types become rare, the voter is informed of the true state $\omega$ when the facts are $\sigma=l$. That is, $\lim _{\eta_{h} \rightarrow 0} \lim _{\eta_{c} \rightarrow 0} \operatorname{Pr}(\omega=l \mid m=l)=1, \lim _{\eta_{h} \rightarrow 0} \lim _{\eta_{c} \rightarrow 0} \operatorname{Pr}(m=l \mid \sigma=l)=1$, and $\Phi_{0}<\frac{1}{4} \gamma$.

It is also possible to show that $\lim _{\gamma \rightarrow 1} \Phi_{0}=0$, i.e., that the strategic distortion is zero in the limit as exogenous information becomes perfect. The reason is that as $\gamma$ rises, the likelihood that an honest journalist

\footnotetext{
${ }^{15}$ Party $l$ is willing to claim if and only if

$$
\Delta_{l}\left(\rho_{l}\right) \equiv \operatorname{Pr}(\omega=l \mid m=\{l, r\})-\operatorname{Pr}(\omega=l \mid m=r) \geq \frac{k}{v},
$$

where

$$
\operatorname{Pr}(\omega=l \mid m=r)=\frac{\eta_{c}}{\eta_{c}+\left(\eta_{c}+\eta_{h} \gamma+\eta_{s} \gamma\left(1-\rho_{l}\right)\right)}
$$

and

$$
\operatorname{Pr}(\omega=l \mid m=\{l, r\})=\frac{(1-\gamma)\left(1-\eta_{c}\right)}{(1-\gamma)\left(1-\eta_{c}\right)+(1-\gamma)\left(1-\eta_{c}\right)+\gamma \eta_{s} \rho_{l}} .
$$

Because $\operatorname{Pr}(\omega=l \mid m=\{l, r\})$ is strictly decreasing in $\rho_{l}$ and $\operatorname{Pr}(\omega=l \mid m=r)$ is strictly increasing in $\rho_{l}, \Delta_{l}\left(\rho_{l}\right)$ is strictly decreasing in $\rho_{l}$ and there is a unique equilibrium $\rho_{l}^{*}$. The extreme cases are

$$
\begin{aligned}
\Delta_{l}(1) & =\frac{(1-\gamma)\left(1-\eta_{c}\right)}{2(1-\gamma)\left(1-\eta_{c}\right)+\gamma \eta_{s}}-\frac{\eta_{c}}{2 \eta_{c}+\eta_{h} \gamma} \\
\Delta_{l}(0) & =\frac{1}{2}-\frac{\eta_{c}}{2 \eta_{c}+\left(1-\eta_{c}\right) \gamma} .
\end{aligned}
$$

If $\Delta_{l}(1) \geq \frac{k}{v}$ then $\rho_{l}^{*}=1$, if $\Delta_{l}(0) \leq \frac{k}{v}$ then $\rho_{l}^{*}=0$, and if $\Delta_{l}(0)>\frac{k}{v}>\Delta_{l}(1)$ then $\rho_{l}^{*} \in(0,1)$.

${ }^{16}$ Because the party's benefit from claiming is continuous in $\eta_{h}$ and $\eta_{c}$, so is $\rho_{l}^{*}$, which means that $\lim _{\eta_{h} \rightarrow 0} \lim _{\eta_{c} \rightarrow 0} \rho_{l}^{*}$ exists. Because the voter's expected loss is continuous in $\eta_{h}, \eta_{c}$, and $\rho_{l}^{*}, \lim _{\eta_{h} \rightarrow 0} \lim _{\eta_{c} \rightarrow 0} \mathrm{E}(L(a(m), \omega))$ also exists.
} 

$l$ 's incentive to claim. ${ }^{17}$

It is interesting that disclosure of the journalist's (or organization's) political preferences may improve communication, because ethical guidelines for journalists commonly prohibit such disclosures. Consider the following quote from the New York Times Ethical Journalism handbook:

Staff members are entitled to vote, but they ... may not campaign for, demonstrate for, or endorse candidates ... They may not wear campaign buttons or themselves display any other insignia of partisan politics. They should recognize that a bumper sticker on the family car or a campaign sign on the lawn may be misread as theirs, no matter who in their household actually placed the sticker or the sign. (New York Times 2004a).

In its Handbook for Journalists During Elections, Reporters Without Borders similarly urges journalists to "express political opinions only in private, preferably with the very closest of friends or family" (Reporters Without Borders 2014). The UK's Broadcasting Codes require that "programs ... must exclude all expressions of the views and opinions of the person providing the service" (Ofcom 2013).

A comparison of propositions 3 and 4 shows the cost of nondisclosure. When a journalist's political leanings are unknown, any unambiguous report may be taken as evidence that the journalist is taking sides, so the only reputationally safe report is an uninformative one. If, on the other hand, the voter knows that, say, the journalist is a card-carrying Republican, the journalist can more confidently state the climate-change consensus. This comparison, which is reminiscent of Cukierman and Tommasi (1998), may help to explain why balance is prevalent in news coverage of climate-change, even (or especially) in newspapers that are generally thought to align with the left. The comparison also begs the question of why news organizations would prohibit public disclosure of leanings in the first place. A possible explanation is that a journalist who is willing to declare her affiliation publicly is perceived as more likely to be captured (ideological) than one who keeps her personal views to herself.

\subsection{Fairness Rules}

In the UK, the Office of Competition's Broadcasting Codes require that news is "presented with due impartiality," meaning that "an appropriately wide range of significant views must be included and given due weight in each program or in clearly linked and timely programs" (Ofcom 2013). In the US, the so-called

\footnotetext{
${ }^{17}$ Note that $\lim _{\gamma \rightarrow 1} \lim _{\eta_{h} \rightarrow 0} \lim _{\eta_{c} \rightarrow 0} \Delta_{l}(0)=\frac{1}{2}$ and $\lim _{\gamma \rightarrow 1} \lim _{\eta_{h} \rightarrow 0} \lim _{\eta_{c} \rightarrow 0} \Delta_{l}\left(\rho_{l}\right)=0$ for any $\rho_{l}>0$. Therefore $\lim _{\gamma \rightarrow 1} \lim _{\eta_{h} \rightarrow 0} \lim _{\eta_{c} \rightarrow 0} \rho_{l}^{*}=0$.
} 

ment the broadcast of all sides of controversial public issues over their facilities" (Federal Communications Commission 1949). ${ }^{18}$

Within the model, define the fairness rule to be a requirement that the message $m$ must include any fact or claim available to the journalist. ${ }^{19}$ Such a rule makes the journalist's problem trivial: strategic and honest types report $m=\sigma \cup j^{*}$, and, if we treat the captured type as always possessing a claim that supports her leaning, then the captured type reports $m=\lambda \cup \sigma \cup j^{*}$.

Parties may now choose to claim in either period of the game. In each period, equation (2) governs the parties' incentives.

To characterize equilibrium in a generic period, note first that if $\frac{k}{v}>\frac{1}{2}$ then no party claims in equilibrium, so that $\operatorname{Pr}(\omega=j \mid m=\{l, r\})=\frac{1}{2}$ and $\operatorname{Pr}(\omega=j \mid m=\sim j)=0$ for all $j .{ }^{20}$ Next, note that if $\frac{k}{v}<\frac{1}{2}$ then both parties claim with probability one in any equilibrium. ${ }^{21}$ That the strategies $\rho_{j}^{*}=1$ for all $j$ constitute an equilibrium follows immediately letting $\operatorname{Pr}(\omega=j \mid m=\{l, r\})=\frac{1}{2}$ and $\operatorname{Pr}(\omega=j \mid m=\sim j)=0$ for all $j .{ }^{22}$ That no other strategies constitute an equilibrium follows because, if $\rho_{j}<1$ for some $j$, then $\operatorname{Pr}(\omega=j \mid m=\sim j)=0$ and, by analogy to equation (2), $\operatorname{Pr}(\omega=j \mid m=\{l, r\})<\frac{1}{2}$, implying a contradiction. $^{23}$

In comparison to the baseline game, when $\frac{k}{v}<\frac{1}{2}$ the voter is strictly worse off with the fairness rule in both periods. The fairness rule eliminates the information in the honest type's report in the first period, and in the honest and strategic types' reports in the second. When $\frac{k}{v}>\frac{1}{2}$ the voter is strictly better off with the fairness rule, because the rule prevents the captured type from making an unambiguous report that contradicts the true state. ${ }^{24}$

Proposition 5. The voter strictly prefers to adopt the fairness rule if the relative cost of claiming is high

\footnotetext{
${ }^{18}$ Although enforcement of the Fairness Doctrine ended in 1987, debate continues about its reinstatement (Ruane 2012). Such policies are also common in other developed countries (Barendt 1993).

${ }^{19}$ Treating facts and claims differently would of course improve the performance of the rule, but would require that the regulator be able to tell the two apart.

${ }^{20}$ If party $j$ claims then the party's incentives require that $\operatorname{Pr}(\omega=j \mid m=\{l, r\})>\frac{1}{2}$. But then party $\sim j$ does not claim, so from Bayes' Rule $\operatorname{Pr}(\omega=j \mid m=\{l, r\})<\frac{1}{2}$, a contradiction.

${ }^{21}$ For completeness, note that in the knife-edge case of $\frac{k}{v}=\frac{1}{2}$ there is a continuum of symmetric strictly mixing equilibria, as well as an equilibrium in which both parties claim with probability one.

${ }^{22}$ Because singleton messages do not occur on the equilibrium path, any beliefs with $\operatorname{Pr}(\omega=j \mid m=\sim j) \in\left[0, \frac{1}{2}-\frac{k}{v}\right]$ will support an equilibrium.

${ }^{23}$ From Bayes' Rule, if $\operatorname{Pr}(\omega=j \mid m=\{l, r\})<\frac{1}{2}$ then $\rho_{\sim j}<\rho_{j}<1$, so $\operatorname{Pr}(\omega=\sim j \mid m=j)=0$, implying the contradiction that $\rho_{\sim j}=1$.

${ }^{24}$ Suppose that $\frac{k}{v}>\frac{1}{2}$. Then the strategic and honest types report $m=\sigma$ with or without the fairness rule. The captured type reports $m=\lambda$ without the fairness rule and $m=\lambda \cup \sigma$ with the fairness rule. Because the leaning $\lambda$ is independent of the true state, under the fairness rule the voter can always garble the message $m$ to reproduce the conditional distribution of the message without the fairness rule. This implies that the voter is no worse off with the fairness rule; that she is strictly better off is easy to show, for example, by deriving expressions for expected loss under the two regimes.
} 
Put differently, when $\frac{k}{v}>\frac{1}{2}$, the fairness rule protects the voter from media capture; when $\frac{k}{v}<\frac{1}{2}$, the fairness rule exposes the voter to possibly illegitimate dissent.

Arguments reminiscent of the tension in proposition 5 have surfaced in recent media policy debates. The 2005 Editorial Guidelines of the British Broadcasting Corporation (BBC) called for a "commitment to impartiality," meaning that the BBC would "strive to reflect a wide range of opinion and explore a range and conflict of views" (Thompson 2005). Partly due to criticism of the BBC's coverage of climate change and other scientific topics (Jones 2011), the guidelines were revised in 2010 to clarify that "minority views should not necessarily be given equal weight to the prevailing consensus" (Lyons 2010).

\section{Extensions and Generalizations}

\subsection{Asymmetric Prior Over States}

The baseline model assumes that $\operatorname{Pr}(\omega=r)=\frac{1}{2}$. Suppose instead that $\operatorname{Pr}(\omega=r)=\operatorname{Pr}(\omega=r \mid m=\{l, r\})=$ $\operatorname{Pr}(\lambda=r)=\theta$ where without loss of generality $\theta \geq \frac{1}{2}$. Suppose also that $\frac{k}{v}<\frac{1}{2}$, which is the more interesting case following proposition 3.

Second-period play is unchanged from the baseline model, and it is straightforward to show that the strategic journalist reports $m=\{l, r\}$ whenever possible in the first period.

In the first period, party $j$ is willing to claim if and only if

$$
\Delta_{j}\left(\rho_{j}, \rho_{\sim j}\right) \equiv \operatorname{Pr}(\omega=j \mid m=\{l, r\})-\operatorname{Pr}(\omega=j \mid m=\sim j) \geq \frac{k}{v}
$$

From Bayes' Rule, for any $\left(\rho_{l}, \rho_{r}\right)$ and any $j, \lim _{\eta_{c} \rightarrow 0} \operatorname{Pr}(\omega=j \mid m=\sim j)=0$, because in the limit as $\eta_{c} \rightarrow 0$, an unambiguous report must come from a strategic or honest journalist.

For $\eta_{c}$ sufficiently small, party $r$ claims with probability 1 in any equilibrium. To see this note first that if $\rho_{r}=0$, from Bayes' Rule $\lim _{\eta_{c} \rightarrow 0} \operatorname{Pr}(\omega=r \mid m=\{l, r\}) \geq \theta$, so that $\lim _{\eta_{c} \rightarrow 0} \Delta_{r}\left(0, \rho_{l}\right) \geq \theta \geq \frac{1}{2}>$ $\frac{k}{v}$ for any $\rho_{l}$. Therefore $\rho_{r}>0$ for $\eta_{c}$ sufficiently small. Next, by complementarity of the probabilities $\operatorname{Pr}(\omega=j \mid m=\{l, r\}), \lim _{\eta_{c} \rightarrow 0}\left(\Delta_{r}\left(\rho_{r}, \rho_{l}\right)+\Delta_{l}\left(\rho_{l}, \rho_{r}\right)\right)=1$ for any $\rho_{l}, \rho_{r}$, and if $\rho_{r} \in(0,1)$ then $\Delta_{r}\left(\rho_{r}, \rho_{l}\right)=$ $\frac{k}{v}$ so $1-\Delta_{r}\left(\rho_{r}, \rho_{l}\right)=1-\frac{k}{v}>\frac{1}{2}>\frac{k}{v}$. Therefore for $\eta_{c}$ sufficiently small, if $\rho_{r} \in(0,1)$ then $\rho_{l}=1$, but by Bayes' Rule $\lim _{\eta_{c} \rightarrow 0} \Delta_{r}\left(\rho_{r}, 1\right) \geq \theta \geq \frac{1}{2}>\frac{k}{v}$ for any $\rho_{r}$, implying a contradiction; hence $\rho_{r}=1$.

To complete the characterization, observe that from Bayes' Rule $\Delta_{l}\left(\rho_{l}, 1\right)$ is strictly decreasing in $\rho_{l}$ 
and that it is strictly decreasing in $\theta$ for $\eta_{c}$ sufficiently small and $\rho_{l} \in(0,1) .{ }^{25}$ It follows that when $\eta_{c}$ is sufficiently small there is a unique probability $\rho_{l}^{*}$ with which party $l$ claims in equilibrium, with $\rho_{l}^{*}=0$ if $\Delta_{l}(0,1)<\frac{k}{v}, \rho_{l}^{*}=1$ if $\Delta_{l}(1,1)>\frac{k}{v}$, and $\rho_{l}^{*} \in(0,1)$ solving $\Delta_{l}\left(\rho_{l}^{*}, 1\right)=\frac{k}{v}$ otherwise. When $\rho_{l}^{*} \in(0,1), \rho_{l}^{*}$ is strictly decreasing in $\theta$. To summarize:

Proposition 6. For priors $\theta \in\left[\frac{1}{2}, 1\right)$, relative costs of claiming $\frac{k}{v}<\frac{1}{2}$, and probability of capture $\eta_{c}$ sufficiently small, there exists a unique equilibrium in which, in the first period, the strategic journalist reports $m=\{l, r\}$ whenever possible, party $r$ claims with probability 1 , and party l claims with unique probability $\rho_{l}^{*}$, which is decreasing in $\theta$, strictly when $\rho_{l}^{*} \in(0,1)$.

In equilibrium, party $r$ claims at least as often as party $l$, and possibly more often. An economic intuition is that, because the voter's prior favors state $r$, party $r$ benefits more from an ambiguous report than does party $l$. For the same reason, when $\theta$ is high, party $l$ benefits little from claiming, because the voter's posterior favors state $r$ even after an ambiguous report.

We can now consider the welfare properties of the equilibrium. Continuity of payoffs and strategies means that $\Phi_{0}$ is well-defined. Because $\lim _{\eta_{c} \rightarrow 0} \Delta_{l}(1,1)=1-\theta$, when $\theta$ is close to $\frac{1}{2}, \rho_{l}^{*}=1$ and the outcome is analogous to that in the baseline game:

Corollary 1. If the relative cost of claiming is low $\left(\frac{k}{v}<\frac{1}{2}\right)$, there exists $\underline{\theta} \in\left(\frac{1}{2}, 1\right)$ such that for all priors $\theta \in\left[\frac{1}{2}, \underline{\theta}\right)$, in the limit as non-strategic types become rare, the voter is completely uninformed, i.e., $\Phi_{0}=$ $\gamma \theta(1-\theta)$.

An implication is that the result in proposition 3 is not a knife-edge with respect to the prior probability of the states.

When $\theta>\underline{\theta}$, the voter is partially informed. However, there remain important limits on what the voter can learn. In particular, observe that if $\sigma=l$ then the strategic journalist always reports $m=\{l, r\}$. Therefore when non-strategic types are rare, the voter can never learn the true state when $\omega=l$ :

Corollary 2. In the limit as non-strategic types become rare, the voter never chooses the ex post optimal policy when the true state is $\omega=l$. That is, there exists $\varepsilon>0$ such that $\lim _{\eta_{h} \rightarrow 0} \lim _{\eta_{c} \rightarrow 0} \operatorname{Pr}(a<\varepsilon)=0$.

\footnotetext{
${ }^{25}$ By Bayes' Rule

$$
\operatorname{Pr}(\omega=l \mid m=r)=\frac{\eta_{c}(1-\theta)}{\eta_{c}+\eta_{h} \gamma+\eta_{s} \gamma\left(1-\rho_{l}\right)}
$$

and, when $\rho_{r}=1$,

$$
\operatorname{Pr}(\omega=l \mid m=\{l, r\})=\frac{(1-\theta)\left(\eta_{h}(1-\gamma)+\eta_{s}\right)}{\eta_{h}(1-\gamma)+\eta_{s}\left((1-\theta)+\theta\left((1-\gamma)+\gamma \rho_{l}\right)\right)} .
$$

It is readily verified that $\operatorname{Pr}(\omega=l \mid m=r)$ is strictly increasing in $\rho_{l}$ and $\operatorname{Pr}(\omega=r \mid m=\{l, r\})$ is strictly decreasing in $\rho_{l}$, so $\Delta_{l}\left(\rho_{l}, 1\right)$ is strictly decreasing in $\rho_{l}$. From these expressions it also follows that $\Delta_{l}\left(\rho_{l}, 1\right)$ is strictly decreasing in $\theta$ when $\eta_{c}$ is sufficiently small and $\rho_{l} \in(0,1)$.
} 

is $\omega=r^{26}$

Corollary 2 shows that, due to special interests' incentives, the voter can never be sure that the state that she regards as less likely ex ante has realized. The result is reminiscent of the literature on pandering (e.g. Prendergast 1993; Brandenburger and Polak 1996; Gentzkow and Shapiro 2006; Che et al. 2013), but the mechanism at work here is different.

\subsection{A Single Interested Party}

The baseline model assumes that the two interested parties are symmetric. Competition between these groups plays an important role in the equilibrium characterized in section 4, because when the voter sees an ambiguous report, she cannot infer which party, if any, has manufactured a false claim. In practice, interest groups may differ in the benefit they get from influencing policy, or in the costs they face of manufacturing evidence.

To see the implications of such asymmetries, consider the extreme case, in which, say, party $l$ is unable to claim. The voter is then at least partially informed, because when the facts are $\sigma=r$ the strategic journalist must report $m=r$ :

Proposition 7. If party l cannot claim, then in the limit as non-strategic types become rare, the voter is partially informed. That is, $\Phi_{0}<\frac{1}{4} \gamma$.

The proof is omitted as it follows the same structure as the proof of proposition 4 . The equilibrium in this game is considerably better for the voter than that in the baseline game. One way to see this is to note that $\lim _{\gamma \rightarrow 1} \Phi_{0}=0$, i.e., the voter is perfectly informed in the limit if it is common knowledge that the journalist knows the true state. (In this limit, $m=\{l, r\}$ implies that $\omega=l$.)

Groups opposing the scientific consensus on climate change have arguably been more active in the media than groups supporting the consensus. This does not mean that the two sides differ in their underlying capabilities. Even in the baseline model, the more active interested party is the one whose position is contradicted by the facts. What distinguishes the baseline model from the variant considered here is not whether the two parties make symmetric investments ex post, but whether they are symmetric ex ante. In practice, environmental groups can and do mobilize resources to cast public doubt on scientific evidence. ${ }^{27}$

\footnotetext{
${ }^{26}$ Because $\lim _{\eta_{c} \rightarrow 0} \Delta_{l}(1,1)=1-\theta$, there exists $\bar{\theta} \in\left[\frac{1}{2}, 1\right)$ such that for all $\theta \in(\bar{\theta}, 1)$, for any $\varepsilon>0$, $\lim _{\eta_{h} \rightarrow 0} \lim _{\eta_{c} \rightarrow 0} \operatorname{Pr}(1-a<\varepsilon)>0$.

${ }^{27} \mathrm{An}$ example is the campaign by Greenpeace and other groups to cast doubt on the safety of genetically modified foods, especially in Europe (Paarlberg 2000; Lynch and Vogel 2001). The topic has received substantial media attention in Europe, and at least some evidence suggests a correlation between media exposure and risk assessment (Vilella-Vila and Costa-Font 2008).
} 

only one side of an issue (say, business interests) can influence the news.

\subsection{General Message Space}

The baseline model assumes a limited message space. In equilibrium, when the facts are unambiguous, a strategic journalist must sacrifice either the informativeness of her report or her reputation for neutrality. A more general message space might improve equilibrium communication by allowing the journalist to sacrifice just enough information to communicate that she is not captured, but not so much that the voter remains uninformed.

The reputational forces highlighted in the model limit the practical scope for such messages. To see why, consider a 1998 Los Angeles Times article reporting that 1997 was the warmest year of the 20th century (Gerstenzang 1998). The article's sub-header conveys an impression of meaningful controversy: "New figures raise concerns about risks of global heating. Some remain skeptical of phenomenon." Suppose that the sub-header instead said: "New figures raise concerns about risks of global heating. Some retired scientists dispute phenomenon." The alternate sub-header is factually accurate and, relative to the actual sub-header, would likely be read to imply stronger evidence in favor of climate change. But the alternate sub-header is also more consistent with the view that the Los Angeles Times has an environmentalist agenda, because an outlet with such an agenda would like to discredit climate skeptics.

The example suggests that there is a tension between neutrality and information even when the message space is fine. It is possible to illustrate this tension formally in a game with a general signal and message space. Suppose there is a state $\omega \in\{l, r\}$ with $\operatorname{Pr}(\omega=r)=\frac{1}{2}$. A journalist gets an informative signal $\sigma$ in some finite set $\mathscr{S}$ and reports a message $m$ in some finite set $\mathscr{M}$ to a voter. The journalist has leaning $\lambda \in$ $\{l, r\}$ with $\operatorname{Pr}(\lambda=r)=\frac{1}{2}$ and $\lambda \perp \omega$. With probability $\eta_{c} \in(0,1)$ the journalist is captured, in which case she chooses $m$ to maximize the posterior probability $\operatorname{Pr}(\omega=\lambda \mid m)$ that the voter assigns to the journalist's preferred state. With probability $1-\eta_{c}$, the journalist is strategic, in which case she chooses $m$ to minimize the posterior probability $\hat{\eta}_{c}(m)$ that the voter assigns to the journalist being captured. (There is no honest type.)

The game has an equilibrium, ${ }^{28}$ and it is possible to establish a general limit on the amount of information the journalist can communicate, irrespective of the message space $\mathscr{M}$ :

The European public is very concerned about the safety of genetically modified foods (Gaskell et al. 2010), more so than area experts (Savadori et al. 2004). Authoritative reviews have not found convincing evidence of harm to humans from consumption of genetically modified foods (see, e.g., Institute of Medicine and National Research Council of the National Academies 2004).

${ }^{28}$ Suppose that all types of journalist randomize uniformly over $\mathscr{M}$. Then $\operatorname{Pr}(\omega=r \mid m)=\frac{1}{2}$ and $\hat{\eta}_{c}(m)=\eta_{c}$ for all $m \in \mathscr{M}$, and no type of journalist has an incentive to deviate. 

equilibrium.

Proof. Toward contradiction, suppose that at least three values of $\operatorname{Pr}(\omega=r \mid m)$ occur with positive probability in equilibrium. Then there must exist distinct messages $m^{\prime}, m^{\prime \prime}$, and $m^{\prime \prime \prime}$ such that, in equilibrium, $\operatorname{Pr}\left(m^{\prime}\right)>0, \operatorname{Pr}\left(m^{\prime \prime}\right)>0, \operatorname{Pr}\left(m^{\prime \prime \prime}\right)>0$, and $\operatorname{Pr}\left(\omega=r \mid m^{\prime}\right)<\operatorname{Pr}\left(\omega=r \mid m^{\prime \prime}\right)<\operatorname{Pr}\left(\omega=r \mid m^{\prime \prime \prime}\right)$.

The captured journalist will never report message $m^{\prime \prime}$ : if her leaning is $\lambda=r$ she strictly prefers to report $m^{\prime \prime \prime}$; if her leaning is $\lambda=l$ she strictly prefers to report $m^{\prime}$. Therefore $\hat{\eta}_{c}\left(m^{\prime \prime}\right)=0$. Because the strategic journalist can report $m^{\prime \prime}$ and attain $\hat{\eta}_{c}\left(m^{\prime \prime}\right)=0$, she will never report any message that is reported with positive probability by the captured type. Because the captured type with leaning $r$ can report $m^{\prime \prime \prime}$ and attain $\operatorname{Pr}\left(\omega=r \mid m^{\prime \prime \prime}\right)$, any message that she reports in equilibrium will yield at least as great a posterior belief that $\omega=r$. Because the captured type with leaning $l$ can report $m^{\prime}$ and attain $\operatorname{Pr}\left(\omega=r \mid m^{\prime}\right)$, any message that she reports in equilibrium will yield no greater a posterior belief that $\omega=r$. It follows that the set $\mathscr{M}_{l}$ of messages reported with positive probability by the captured type with leaning $l$, the set $\mathscr{M}_{r}$ of messages reported by the captured type with leaning $r$, and the set $\mathscr{M}_{0}$ of messages reported by the strategic type, are disjoint.

Because the event that $m \in \mathscr{M}_{r}$ is independent of $\omega$, the posterior belief that $\omega=r$ given that $m \in \mathscr{M}_{r}$ is $\frac{1}{2}$. Because all messages in $\mathscr{M}_{r}$ must induce the same posterior belief on $\omega$, any given message in $\mathscr{M}_{r}$ must induce posterior $\frac{1}{2}$, implying that $\operatorname{Pr}\left(\omega=r \mid m^{\prime \prime \prime}\right) \leq \frac{1}{2}$. An analogous argument shows that $\operatorname{Pr}\left(\omega=r \mid m^{\prime}\right) \geq \frac{1}{2}$, a contradiction.

As an application of proposition 8, consider the signal structure of the baseline model, in which $\sigma$ can take on three possible values. Proposition 8 means that, no matter how fine the message space, the journalist's report is strictly less informative than the signal.

In practice, the fineness of journalistic communication is limited not only by reputational forces, but also by voter inattention. Citizens recall very little detail from the news reports that they see and read. ${ }^{29}$ To an inattentive voter, even a carefully worded nod to climate skeptics may suggest ambiguity in the evidence. In the Los Angeles Times article that I discuss above, it is not until the eighth paragraph that the article explains that the "vocal skeptics" cited in the sub-header are "an organization of mostly retired academics." While this language might lead a careful reader to give less weight to skeptics' claims, a casual reader could easily

\footnotetext{
${ }^{29}$ Neuman (1976) found that survey respondents in the San Francisco Bay Area could, with prompting, recall meaningful details for only one-quarter of the stories they saw on the evening news, even though the survey was conducted that same evening. Robinson and Davis (1990) found in a national sample that adults comprehended only about a third of the important news stories from the previous week, with readers of print media only slightly outperforming the average. d'Haenens et al. (2004) find that recall is, if anything, lower from online media than from traditional print media.
} 
come away with the impression of meaningful controversy about whether greenhouse gases are warming the earth.

\subsection{Reputation for Honesty}

In the baseline model, the journalist is concerned only about convincing the voter that she is not captured. The journalist therefore makes ambiguous reports whenever possible. Here I consider what happens when the journalist is instead concerned with appearing honest. I first present results assuming a reduced-form payoff function for the journalist. I then provide microfoundations that deliver additional predictions about the types of issues on which reporting will be informative.

Suppose that there is a single period in which the strategic journalist's payoff is some $\pi\left(\hat{\eta}_{h}(m, \omega)\right)$, where $\pi()$ is a strictly increasing function and $\hat{\eta}_{h}(m, \omega)$ is the voter's posterior belief that the journalist is honest. ${ }^{30}$ To focus on the concern for appearing honest, I assume there is no captured type. All other details are as in the baseline model.

In any equilibrium of this modified game, the strategic journalist reports $m=\sigma$ and the parties do not claim. To see this, note first that if, on the equilibrium path, the journalist sometimes reports a singleton $m^{\prime} \notin \sigma^{\prime}$ when the facts are $\sigma^{\prime}$, then there is some $\omega^{\prime}$ such that $\operatorname{Pr}\left(\omega^{\prime} \notin m^{\prime} \mid \sigma^{\prime}\right)=1$. But then $\hat{\eta}_{h}\left(m^{\prime}, \omega^{\prime}\right)=0$ and $\hat{\eta}_{h}\left(\sigma^{\prime}, \omega^{\prime}\right)>0$ so the journalist wishes to deviate to reporting $\sigma^{\prime}$. Therefore in equilibrium any report by the strategic journalist satisfies $m \cap \sigma \neq \emptyset .^{31}$

The next step is to show that the strategic journalist reports $m=\{l, r\}$ when $\sigma=\{l, r\}$. Suppose that instead the strategic journalist sometimes reports $m=r$ when $\sigma=\{l, r\}$. Then

$$
\frac{1}{2} \pi\left(\hat{\eta}_{h}(r, r)\right)+\frac{1}{2} \pi\left(\hat{\eta}_{h}(r, l)\right) \geq \frac{1}{2} \pi\left(\hat{\eta}_{h}(\{l, r\}, r)\right)+\frac{1}{2} \pi\left(\hat{\eta}_{h}(\{l, r\}, l)\right) .
$$

Because $\hat{\eta}_{h}(r, l)=0$ it must be that $\hat{\eta}_{h}(r, r)>\hat{\eta}_{h}(\{l, r\}, r)$, so that the strategic journalist always reports $m=r$ when $\sigma=r$. But then from Bayes' Rule $\hat{\eta}_{h}(\{l, r\}, r) \geq \eta_{h} \geq \hat{\eta}_{h}(r, r)$, a contradiction.

What remains is to show that the strategic journalist does not report $m=\{l, r\}$ when $\sigma \neq\{l, r\}$. Suppose

\footnotetext{
${ }^{30}$ As there is no longer a need to pin down second-period play, I drop for this subsection the refinement that the strategic journalist reports $m=\sigma$ when indifferent.

${ }^{31}$ Let $\beta(m, \sigma)$ denote the probability that the strategic journalist reports $m$ when the facts are $\sigma$. The strategic journalist's reporting is fully characterized by $(\beta(r, r), \beta(l, l), \beta(r,\{l, r\}), \beta(l,\{l, r\}))$. By Bayes' Rule:
}

$$
\begin{gathered}
\hat{\eta}_{h}(r, r)=\frac{\eta_{h} \gamma}{\eta_{h} \gamma+\left(1-\eta_{h}\right)(\gamma \beta(r, r)+(1-\gamma) \beta(r,\{l, r\}))} \\
\hat{\eta}_{h}(\{l, r\}, r)=\frac{\eta_{h}(1-\gamma)}{\eta_{h}(1-\gamma)+\left(1-\eta_{h}\right)(\gamma(1-\beta(r, r))+(1-\gamma)(1-\beta(r,\{l, r\})-\beta(l,\{l, r\})))} .
\end{gathered}
$$


to the contrary that the strategic journalist sometimes reports $m=\{l, r\}$ when $\sigma=r$. Then because the strategic journalist always reports $m=\{l, r\}$ when $\sigma=\{l, r\}$, Bayes' Rule implies that $\hat{\eta}_{h}(r, r)>\eta_{h}>$ $\hat{\eta}_{h}(\{l, r\}, r)$, a contradiction.

Proposition 9. When the strategic journalist is concerned only with appearing honest, there is no policy distortion.

The result in proposition 9 is not a knife-edge. The online appendix proves that there is no distortion in the limit as the concern for appearing honest becomes large relative to the concern for appearing not to be captured. The online appendix also proves that the equilibrium of the baseline game emerges in the limit as the concern for appearing honest becomes small relative to the concern for appearing not to be captured.

To microfound the reduced-form payoff function $\pi\left(\hat{\eta}_{h}(m, \omega)\right)$, return to the baseline game. Suppose that $\eta_{c}=0$ but there is a strictly positive probability that a strategic journalist will become captured prior to the second period, say because she is bribed or otherwise influenced by one of the parties. We may think of this as a case in which the first period's issue is apolitical in the sense that capture is relatively unlikely in the first compared to the second period. Because only the strategic type is subject to capture, the journalist's payoff at the beginning of the second period is a strictly increasing function of $\hat{\eta}_{h}(m, \omega)$, and proposition 9 applies:

Corollary 3. There is no policy distortion in reporting on an apolitical issue.

Proposition 9 also applies to the case in which reporting is costly. Suppose that $\eta_{c}=0$ but there is a strictly positive probability that the strategic journalist will make no report at all in the second period, say because the costs of reporting are especially high. If the honest type is sure to make a report, then the journalist's first-period payoff is a strictly increasing function of $\hat{\eta}_{h}(m, \omega)$, and proposition 9 applies.

In general, a concern for being perceived as honest arises whenever the strategic journalist's secondperiod report is not as informative as that of the honest type. When this occurs and the risk of capture is low, proposition 9 predicts informative reporting.

\section{Evidence on Model Implications}

The model links public ignorance on climate change to influence activities by special interests and reputational incentives on the part of journalists. This section presents qualitative and quantitative evidence that special interests and the news media do indeed play an important role in driving public opinion and public policy. 
To set the stage, figure 1 shows trends over time in US public opinion about climate change. After a period of growing acceptance of climate change, the US public's beliefs largely stopped converging towards those of experts in the 2000s. This is true despite growing media attention to climate change (Boykoff 2011; Grundmann and Scott 2014), and despite no overall trend in factual knowledge of science (National Science Board 2010). Figure 2 shows that the US public is the least accepting of anthropogenic climate change among OECD countries. Correspondingly, the US performs poorly among rich countries in international ratings of carbon dioxide emissions and abatement (Hsu et al. 2014).

\subsection{Role of Special Interests}

Propositions 2 and 3 say that public policy will better incorporate the available information when special interests have weaker incentives to manipulate public opinion, i.e., when $\frac{k}{v}$ is large.

Climate change is an issue with large policy stakes $v$ : the economic changes required to mitigate carbon emissions will be costly to many actors in the economy. Ozone depletion affords a comparison with much lower $v$. In the early 1970s, evidence emerged that chlorofluorocarbons (CFCs) deplete atmospheric ozone (Dotto and Schiff 1978). Substitutes for CFCs were readily available for many purposes, and abatement costs were correspondingly small (Dotto and Schiff 1978; Palmer et al. 1980).

In the model, a lower $v$ leads to more accurate (less ambiguous) media coverage, a better informed public, and a more appropriate policy response. As predicted, although industrial producers of CFCs initially mounted an organized public relations campaign (Dotto and Schiff 1978), during the 1970s voices from academia and the government dominated those from industry (Andersen and Sarma 2002), consumers of aerosol spray cans substituted rapidly to sprays using non-CFC propellants, and the US banned non-essential uses of CFCs (Dotto and Schiff 1978; Morrisette 1989).

International comparisons are also instructive. In contrast to the case of climate change, the US played a leading role in securing international cooperation on CFC reductions, whereas many European countries initially opposed aggressive action (Sunstein 2007). Some scholars have argued that these differences arose because US chemicals firms were in a better position to market alternatives to CFCs than were their European counterparts (Sunstein 2007). ${ }^{32}$ In the language of the model, the policy stakes $v$ were higher in Europe than in the US.

While $v$ is most easily thought of as a material payoff, special interests may also have non-material motives. Consider, for example, the controversy over the connection between autism and measles, mumps,

\footnotetext{
${ }^{32}$ After initially resisting calls for CFC reductions, in the mid-1980s DuPont publicly supported an international treaty restricting CFC production, a move that some interpret as a reflection of DuPont's advances over its competitors in developing CFC alternatives (Litfin 1994; Levy and Newell 2000).
} 
and rubella (MMR) vaccination in children. In 1998, UK physician Andrew Wakefield publicly raised the possibility of a causal connection between the MMR vaccine and autism (Mnookin 2012). Subsequent authoritative reviews of the medical evidence have found no support for such a connection (Institute of Medicine 2004; Demicheli et al. 2012), but an organized opposition to this consensus has emerged (Mnookin 2012). Although there are financial stakes - thousands of US families have filed for compensation for harm done by the MMR vaccine (Sugarman 2007) ${ }^{33}$ —in many cases activists seem to be motivated more by personal conviction than by financial self-interest (Mnookin 2012). ${ }^{34}$ As in the case of climate change, the media have given significant coverage to non-consensus views, ${ }^{35}$ especially in the UK, where the hypothesis of an MMR-autism link gained traction with the public, ${ }^{36}$ and levels of childhood MMR vaccine coverage fell significantly (Burgess et al. 2006). ${ }^{37}$

\subsection{Role of the News Media}

Proposition 3 predicts that the news media will be uninformative on controversial issues in which special interests are active. Table 1 shows that the prediction is borne out in recent polling data: those who read a newspaper daily are only slightly (and statistically insignificantly) more likely to report that there is "solid evidence that the earth has been getting warmer." The table shows that this is true for Republicans, Democrats, and Independents, indicating that the pattern does not reflect a partisan bias in the processing of information.

This finding is surprising, as a large body of past work consistently finds that those who consume print media are better informed about current events than those who do not (e.g., Finnegan and Viswanath 1996). Tables 1 and 2 show that, indeed, news readers are better informed about uncontroversial facts than nonnews-readers. For example, those who read a newspaper daily are 18 percentage points more likely to know the majority party in the US House than those who do not, and those who follow the news closely are 22 percentage points more likely to know that fracking is a process for extracting natural gas than those who

\footnotetext{
${ }^{33}$ Wakefield's initial interest in the effects of the measles vaccine may have grown out of an attempt to sue vaccine manufacturers (Deer 2011).

${ }^{34}$ This conviction has proved a powerful driver of public activism. Following an ethics ruling against Wakefield by the UK's General Medical Council (GMC), activist groups rallied behind Wakefield (Cox and ABC News Medical Unit 2010; Dominus 2011), with one organization calling the events surrounding the GMC ruling a "vaccine-industry funded media circus" (Williams 2011).

${ }^{35}$ In the UK, nearly one-third of articles on the subject from 1998 to 2006 presented arguments both in favor of and against an MMR-autism link (Clarke 2008; see also Boyce 2006).

${ }^{36}$ Lewis and Speers (2003) present survey evidence that 53 percent of British adults believe that there is "equal evidence on both sides of the [MMR-autism] debate" (Lewis and Speers 2003). Dixon and Clarke (2013) present experimental evidence that reading a balanced news account of the MMR-autism link makes laboratory participants more uncertain about the link and more likely to believe that experts are divided.

${ }^{37}$ Vaccination decisions have meaningful private and public health consequences: in 2012, measles cases in England and Wales reached their highest levels in decades (BBC 2013).
} 

warming between news readers and non-news-readers.

If media reports are an important influence on public opinion, we should expect the public to be better informed about climate change when reporting is less balanced. Table 3 shows that this prediction is borne out in comparisons across the four countries surveyed by Donsbach and Klett (1993). In Germany, 60 percent of the public believes that rising temperatures have a human cause, as compared with 36 percent in the US. Correspondingly, only 2 percent of articles about climate change in the German press mention skeptical scientists, compared with 24 percent in the US.

This relationship could reflect reverse-causality from beliefs about climate change to reporting. One piece of evidence that argues against this interpretation is that differences across countries in climate-change reporting are correlated with differences in general journalistic practices outside the climate-change context. Table 3 shows that US journalists are nearly twice as likely as their German counterparts to say that objectivity means "express[ing] fairly the position of each side in a political dispute." 38 These differences are thought to have originated long before the climate-change issue (Donsbach and Klett 1993). Appendix figure 1 shows that the relationship between journalistic practice and public opinion on climate change is present in a larger (though still small) sample of countries than that in table 3.

Although it is outside the scope of this article to explain cross-country differences in reporting practices, it is noteworthy that German reporters are several times more likely than US reporters to also write editorial commentary (Donsbach 1995). In light of proposition 4, it may be that news is more informative in countries whose reporters are more open about their personal opinions.

\section{Alternative Explanations}

The preceding section shows that the forces highlighted by the model are consistent with several stylized facts about reporting and public views on climate change and other issues. In this section I consider other forces that may also account for these facts. While these forces are important, I argue that they fail to explain or capture important aspects of the media's framing of climate change and other issues.

\subsection{Voter Ideology and Media Slant}

Past evidence shows that ideology influences stated beliefs about objective facts (Prior et al. 2015; Campbell and Kay 2014; Kahan 2015) and that news outlets cater to the predispositions of their audience (Gentzkow

\footnotetext{
${ }^{38}$ Among German journalists, the most common answer is that objectivity means "go[ing] beyond the statements of the contending sides to the hard facts of a political dispute" (Donsbach and Klett 1993).
} 
and Shapiro 2010). In this light, an important alternative to this paper's account of the evidence is that citizens' reported beliefs about climate change reflect their ideological predispositions, and that balance in the news media is simply a reflection of the ideology of the US audience.

Several facts stand out as difficult to reconcile with this account. One is the contrast between ozone depletion and climate change. The fact that the US was a leader in CFC abatement, for example, refutes the hypothesis that the US stance on climate change arises from an intrinsic bias against environmental regulation.

Likewise, if the only force at work is that news media are slanted towards their readers' predispositions, we might expect that news readers would be better informed about climate change among some ideological subgroups, but table 1 (and additional supporting evidence in the online appendix) shows that this is not the case.

Finally, the online appendix shows that proxies for specific ideological factors do not correlate with beliefs about climate change in a cross-section of countries. The public's belief in climate change is not positively correlated with the share of social spending in GDP, as we would expect if climate-change beliefs reflected a general preference for government intervention. The public's belief in climate change is not positively correlated with its belief in human evolution, as we would expect if climate-change beliefs reflect general attitudes toward science. (Correspondingly, news media are probably a less important channel for learning about evolution than for learning about climate change.) The public's belief in climate change is not negatively correlated with the carbon intensity of the country's economy, as we would expect if beliefs were purely self-serving. According to the account in the model, it is rather the combination of high stakes and balanced news media that result in the US public being the most climate-skeptical in the OECD.

Stepping back from the climate change case, an important empirical question is how often media reports depict both sides of an issue and how often they hew to ideological or partisan categories. Although it is beyond the scope of this paper to answer this question systematically, it is interesting to note that even on highly politically divisive issues media outlets seem to give their audiences access to competing views. For example, Fryberg et al. (2012) study a sample of newspaper articles reporting on proposed legislation to toughen enforcement against illegal immigrants living in Arizona. The most commonly reported pro-legislation argument was a concern over public safety. As expected, this argument was mentioned in a greater percentage of articles in conservative newspapers (34.6 percent) than in liberal newspapers (23.1 percent). However, across all of the arguments classified, the most commonly reported was the anti-legislation argument that the law would encourage racial profiling, which was mentioned in a majority of articles in both conservative (54.9 percent) and liberal (55.3 percent) newspapers. Moreover, conservative newspaper 

legal immigrants) than the third most common pro-legislation argument (an appeal to general social welfare). In this case, press accounts exhibit partisan divides, but also a tendency to offer the reader a portrait of competing positions.

\subsection{Other Alternative Explanations}

Entertainment. A possible account of persistent ignorance about climate change is that a desire to entertain leads the news media to exaggerate scientific controversy, creating a misleading impression of uncertainty over consensus facts. There is doubtless some truth to this idea: Televised debates are fun to watch, and Americans even rate uncivil debates as more entertaining than civil ones (Mutz and Reeves 2005).

Yet some patterns in the data seem to fit less naturally with this story. One is that, as I note in section 2, ethical guidelines for journalists often emphasize the need for balance or diversity. If the purpose of balanced coverage is to entertain the audience, as opposed to protecting the reputation of the organization or profession, it is hard to see why news organizations or professional societies feel a need to treat it as an ethical matter.

In addition, while controversy is entertaining in a televised debate, it seems much less so in a print article. Although I have no hard evidence, I submit that the headline "1997 ranks as warmest year of the century. New figures raise concerns about risks of global heating. Some remain skeptical of phenomenon" (Gerstenzang 1998) would be no less entertaining without the final sentence. Yet balanced reporting of the kind reflected in this headline was for a long time the norm in the US press (Boykoff and Boykoff 2004; Grundmann and Scott 2014).

Finally, this explanation does not provide a good account of the cross-country variation in beliefs about climate change, as US news media are not generally found to be more focused on entertainment than news media in other countries. ${ }^{39}$

Access to Sources. Quoting a source can help a journalist ensure future access to that source (Gans 1979, chapter 4). A journalist may therefore reflexively quote both sides of an issue in order to maintain the option to do so in the future. Although this may explain some of the tendency toward balanced reporting, it does not fit with some of the facts. In the case of climate change, many prominent skeptics are not practicing climate scientists and are therefore unlikely to be able to offer scoops on, say, developments at the frontiers of science. Moreover, quoting both side of an issue entails some cost to the journalist, because the source on

\footnotetext{
${ }^{39}$ Brekken et al. (2012) find that the fraction of hard news in US television news and newspapers compares favorably to that in five European countries. Curran et al. (2009) find that US commercial television news is "softer" than the public television news in three European countries, but that US newspapers have a far larger share of "hard" news than the newspapers in those countries.
} 
one side may prefer not to be contradicted by a quote from the other. Indeed, in some cases pressure from sources has been explicitly linked to excessively one-sided reporting (Foer 2004).

Journalists' Information. In the model, the strategic journalist is informed of the extant facts and makes ambiguous reports to avoid appearing to favor one side of the debate. In practice, another possibility is that on some issues journalists are uncertain about the strength of the evidence, and report both sides either to avoid taking a stand that turns out to be wrong, or because they simply don't have enough information to tell which side has the stronger claim to the truth.

In the case of climate change, there is direct evidence that the inclusion of climate skeptics in media reports does not result from journalists' own doubts about the facts. In a survey of climate journalists in five countries including the US, Brüggemann and Engesser (2014) find that while only 14 percent believe that climate change skeptics have "important alternative viewpoints," more than one-third believe that skeptics should receive equal treatment from the media, and a majority believe that skeptics' voices should not be excluded from media reports. A large majority of those surveyed endorse key tenets of the IPCC consensus. Sundblad et al. (2009) find that the average Swedish environmental journalist's confidence on key facts about the state and cause of climate change is within one standard deviation of that of the average scientific expert.

\section{Conclusions}

I present a model of media communication of policy-relevant information to a voter in the presence of special interests. The model contains two key frictions. The first is that special interests can make claims of fact that appear credible to the voter. The second is that the journalist has reputational concerns for appearing neutral. I show that these two frictions can interact to prevent the voter from learning useful facts. Neither friction on its own is sufficient to deliver this outcome. The model delivers new predictions about when public policy will reflect the best available information, and new implications for the design of media institutions. I show that the model can help interpret patterns of media coverage and public opinion on climate change and other domains of policy-relevant science. 


\section{References}

Anderegg, William R. L., James W. Prall, Jacob Harold, and Stephen H. Schneider. 2010. Expert credibility in climate change. Proceedings of the National Academy of Sciences 107(27): 12107-12109.

Andersen, Stephen O. and K. Madhava Sarma. 2002. Protecting the Ozone Layer: The United Nations History. London; Sterling, VA: Routledge.

Austen-Smith, David and John R. Wright. 1992. Competitive lobbying for a legislator's vote. Social Choice and Welfare 9(3): 229-257.

Barendt, Eric M. 1993. Broadcasting Law: A Comparative Study. Oxford: Clarendon Press.

BBC. 2013. Measles outbreak in maps and graphics. May 2, 2013. Accessed at $<$ http://www.bbc.co.uk/news/health-22277186> on November 21, 2013.

Becker, Gary S. 1983. A theory of competition among pressure groups for political influence. Quarterly Journal of Economics 98(3): 371-400.

Bennedsen, Morten and Sven E. Feldmann. 2002. Lobbying legislatures. Journal of Political Economy 110(4): 919-946.

Boyce, Tammy. 2006. Journalism and expertise. Journalism Studies 7(6): 889-906.

Boykoff, Maxwell T. and Jules M. Boykoff. 2004. Balance as bias: Global warming and the US prestige press. Global Environmental Change 14(2): 125-136.

Boykoff, Maxwell T. 2008. Lost in translation? United States television news coverage of anthropogenic climate change, 1995-2004. Climatic Change 86(1-2): 1-11.

- 2011. Who Speaks for the Climate? Making Sense of Media Reporting on Climate Change. Cambridge, UK: Cambridge University Press.

Brandenburger, Adam and Ben Polak. 1996. When managers cover their posteriors: Making the decisions the market wants to see. RAND Journal of Economics 27(3): 523-541.

Brekken, Tove, Kjersti Thorbjørnsrud, and Toril Aalberg. 2012. News substance: The relative importance of soft and de-contextualized news. In Aalberg, Toril and James Curran, eds., How Media Inform Democracy: A Comparative Approach. New York: Routledge.

Brüggemann, Michael and Sven Engesser. 2014. Between consensus and denial: Climate journalists as interpretive community. Science Communication 36(4): 1-29.

Burgess, David C., Margaret A. Burgess, and Julie Leask. 2006. The MMR vaccination and autism controversy in United Kingdom 1998-2005: Inevitable community outrage or a failure of risk communication? Vaccine 24(18): 3921-3928.

Callander, Steven. 2008. A theory of policy expertise. Quarterly Journal of Political Science 3(2): 123-140.

Campbell, Troy H. and Aaron C. Kay. 2014. Solution aversion: On the relation between ideology and motivated disbelief. Journal of Personality and Social Psychology 107(5): 809-824.

Che, Yeon-Koo, Wouter Dessein, and Navin Kartik. 2013. Pandering to persuade. American Economic Review 103(1): 47-79.

Check, William A. 1987. Beyond the political model of reporting: Nonspecific symptoms in media communication about AIDS. Reviews of Infectious Diseases 9(5): 987-1000.

Clarke, Christopher E. 2008. A question of balance: The autism-vaccine controversy in the British and American elite press. Science Communication 30(1): 77-107.

Cox, Lauren and ABC News Medical Unit. 2010. Doctor who started vaccine, autism debate in ethics row. $A B C$ News, February 1, 2010. Accessed at $<$ http://abcnews.go.com/Health/AutismNews/autism-british-doctor-andrew-wakefield-started-autismvaccine-debate-ethics-debacle/story?id=9713197\#.UdSHCvm1Hlc > on July 3, 2013.

Cukierman, Alex and Mariano Tommasi. 1998. When does it take a Nixon to go to China? American Economic Review 88(1): 180-197. 
Dearing, James W. 1995. Newspaper coverage of maverick science: Creating controversy through balancing. Public Understanding of Science 4(4): 341-361.

Deer, Brian. 2011. Secrets of the MMR scare: How the vaccine crisis was meant to make money. British Medical Journal 342: 136-142.

Demicheli, Vittorio, Alessandro Rivetti, Maria Grazia Debalini, and Carlo Di Pietrantonj. 2012. Vaccines for measles, mumps and rubella in children. Cochrane Database of Systematic Reviews 2012(2): CD004407.

Demichelis, Stefano and Jörgen W. Weibull. 2008. Language, meaning, and games: A model of communication, coordination, and evolution. American Economic Review 98(4): 1292-1311.

Dewatripont, Mathias and Jean Tirole. 1999. Advocates. Journal of Political Economy 107(1): 1-39.

d'Haenens, Leen, Nicholas Jankowski, and Ard Heuvelman. 2004. News in online and print newspapers: Differences in reader consumption and recall. New Media and Society 6(3): 363-382.

Dixon, Graham N. and Christopher E. Clarke. 2013. Heightening uncertainty around certain science: Media coverage, false balance, and the autism-vaccine controversy. Science Communication 35(3): 358382.

Dominus, Susan. 2011. The crash and burn of an autism guru. New York Times, April 20, 2011.

Donsbach, Wolfgang and Bettina Klett. 1993. Subjective objectivity. How journalists in four countries define a key term of their profession. International Communication Gazette 51(1): 53-83.

Donsbach, Wolfgang. 1995. Lapdogs, watchdogs and junkyard dogs. Media Studies Journal 9(3): 17-30.

Doran, Peter T. and Maggie Kendall Zimmerman. 2009. Examining the scientific consensus on climate change. Eos, Transactions American Geophysical Union 90(3): 22-23.

Dotto, Lydia and Harold Schiff. 1978. The Ozone War. New York: Doubleday.

Drope, Jacqui and Simon Chapman. 2001. Tobacco industry efforts at discrediting scientific knowledge of environmental tobacco smoke: A review of internal industry documents. Journal of Epidemiology and Community Health 55(8): 588-594.

Ely, Jeffrey C. and Juuso Välimäki. 2003. Bad reputation. Quarterly Journal of Economics 118(3): 785814.

Environmental Tobacco Smoke Working Group. 1988. ETS and indoor air quality. Legacy Tobacco Documents Library Document No. 400113620-400113627. Accessed at <http://legacy.library.ucsf.edu/tid/ocj42a99/pdf?search=\%22400113620\%22> on April 29, 2015.

Federal Communications Commission. 1949. In the matter of editorializing by broadcast licensees: Report of the commission. Washington D.C.

Fico, Frederick, John D. Richardson, and Steven M. Edwards. 2004. Influence of story structure on perceived story bias and news organization credibility. Mass Communication and Society 7(3): 301318.

Finnegan Jr., John R. and Kasisomayajula Viswanath. 1996. The knowledge gap hypothesis: Twenty-five years later. In Brant R. Burleson, ed. Communication Yearbook 19: 187-227. Thousand Oaks, CA: SAGE Publications, Inc.

Foer, Franklin. 2004. The source of the trouble. New York Magazine, June 7, 2004. Accessed at $<$ http://nymag.com/nymetro/news/media/features/9226/> on July 1, 2014.

Fryberg, Stephanie A., Nicole M. Stephens, Rebecca Covarrubias, Hazel Rose Markus, Erin D. Carter, Giselle A. Laiduc, and Ana J. Salido. 2012. How the media frames the immigration debate: The critical role of location and politics. Analyses of Social Issues and Public Policy 12(1): 96-112. 
Mazur, Allan. 1973. Disputes between experts. Minerva 11(2): 243-262.

McCright, Aaron M. and Riley E. Dunlap. 2000. Challenging global warming as a social problem: An analysis of the conservative movement's counter-claims. Social Problems 47(4): 499-522.

Michaels, David. 2008. Doubt is Their Product: How Industry's Assault on Science Threatens Your Health. New York: Oxford University Press.

Mnookin, Seth. 2012. The Panic Virus: The True Story Behind the Vaccine-Autism Controversy. New York: Simon and Schuster.

Morris, Stephen. 2001. Political correctness. Journal of Political Economy 109(2): 231-265.

Morrisette, Peter M. 1989. The evolution of policy responses to stratospheric ozone depletion. Natural Resources Journal 29: 793-820.

Mutz, Diana C. and Byron Reeves. 2005. The new videomalaise: Effects of televised incivility on political trust. American Political Science Review 99(1): 1-15.

National Science Board. 2010. Science and engineering indicators 2010. Arlington, VA: National Science Foundation. Accessed at <http://www.nsf.gov/statistics/seind10/pdfstart.htm > on December 16, 2011.

Neuman, W. Russell. 1976. Patterns of recall among television news viewers. Public Opinion Quarterly 40(1): 115-123.

New York Times. 2004a. Ethical journalism: A handbook of values and practices for the news and editorial departments. Accessed at <http://www.nytco.com/wp-content/uploads/NYT_Ethical_Journalism_09041.pdf $>$ on April 3, 2015.

. 2004b. The Times and Iraq. New York Times, May 26, 2004. 
Nisbet, Matthew C. and Teresa Myers. 2007. Twenty years of public opinion about global warming. Public Opinion Quarterly 71(3): 444-470.

NIPCC. 2011. About the NIPCC. Accessed at $<$ http://www.nipccreport.org/about/about.html> on July 30, 2011.

Ofcom. 2013. Broadcasting code guidance notes: Section five — Due impartiality and due accuracy and undue prominence of views and opinions. Accessed at $<$ http://stakeholders.ofcom.org.uk/broadcasting/broadcast-codes/broadcast-code/impartiality/> on June 2, 2014.

Okrent, Daniel. 2004. Weapons of mass destruction? Or mass distraction? New York Times, May 30, 2004.

Oreskes, Naomi. 2004. The scientific consensus on climate change. Science 306(5702): 1686.

Oreskes, Naomi and Erik M. Conway. 2010. Merchants of Doubt: How a Handful of Scientists Obscured the Truth on Issues from Tobacco Smoke to Global Warming. New York: Bloomsbury Press.

Ottaviani, Marco and Peter Norman Sørensen. 2006. Reputational cheap talk. RAND Journal of Economics 37(1): 155-175.

Paarlberg, Robert. 2000. The global food fight. Foreign Affairs 79(3): 24-38.

Painter, James and Teresa Ashe. 2012. Cross-national comparison of the presence of climate skepticism in the print media in six countries, 2007-10. Environmental Research Letters 7(4): 1-8.

Palmer, Adele R., W. E. Mooz, Timothy H. Quinn, and Kathleen A. Wolf. 1980. Economic Implications of Regulating Chlorofluorocarbon Emissions from Nonaerosol Applications. Santa Monica, CA: Rand Corporation.

Peltzman, Sam. 1976. Toward a more general theory of regulation. Journal of Law and Economics 19(2): 211-240.

Petrova, Maria. 2012. Mass media and special interest groups. Journal of Economic Behavior \& Organization 84(1): 17-38.

Pew Research Center for the People and the Press. 2013. Datasets. Accessed at $<$ http://www.peoplepress.org/category/datasets/> between February 18, 2010 and October 15, 2013.

Prendergast, Canice. 1993. A theory of "yes men." American Economic Review 83(4): 757-770.

Prior, Markus, Gaurav Sood, and Kabir Khanna. 2015. You cannot be serious: The impact of accuracy incentives on partisan bias in reports of economic perceptions. Quarterly Journal of Political Science 10(4): 489-518.

RTDNA. 2013. RTDNA code of ethics. Accessed at $<$ http://www.rtdna.org/content/rtdna_code_of_ethics> on March 1, 2013.

Ray, Julie and Anita Pugliese. 2011. Worldwide, blame for climate change falls on humans. Gallup, April 22, 2011. Accessed at <http://www.gallup.com/poll/147242/Worldwide-Blame-Climate-ChangeFalls-Humans.aspx?version=print $>$ on September 25, 2013.

Reporters Without Borders. 2014. Handbook for journalists during elections. Accessed at $<$ http://en.rsf.org/IMG/pdf/handbook_for_journalists_during_elections_.pdf > on March 21, 2015.

Revkin, Andrew C. 2000. Study faults humans for large share of global warming. New York Times, July 14, 2000.

Robinson, John P. and Dennis K. Davis. 1990. Television news and the informed public: An informationprocessing approach. Journal of Communication 40(3): 106-119.

Ruane, Kathleen Ann. 2012. Fairness doctrine: History and constitutional issues. Journal of Current Issues in Media and Telecommunications 4(3): 189-202.

Saad, Lydia. 2013. Americans' concerns about global warming on the rise. Gallup, April 8, 2013. Accessed at $<$ http://www.gallup.com/poll/161645/americans-concerns-global-warming-rise.aspx $>$ on October 22, 2013.

Savadori, Lucia, Stefania Savio, Eraldo Nicotra, Rino Rumiati, Melissa Finucane, and Paul Slovic. 2004. Expert and public perception of risk from biotechnology. Risk Analysis 24(5): 1289-1299. 
Schudson, Michael. 2001. The objectivity norm in American journalism. Journalism 2(2): 149-170.

Sobbrio, Francesco. 2011. Indirect lobbying and media bias. Quarterly Journal of Political Science 6(3-4): 235-274.

Stigler, George J. 1971. The theory of economic regulation. Bell Journal of Economics and Management Science 2(1): 3-21.

Stone, Daniel F. 2011. A signal-jamming model of persuasion: Interest group funded policy research. Social Choice and Welfare 37(3): 397-424.

Strömberg, David. 2001. Mass media and public policy. European Economic Review 45(4-6): 652-663.

Sugarman, Stephen D. 2007. Cases in vaccine court - Legal battles over vaccines and autism. New England Journal of Medicine 357(13): 1275-1277.

Sundblad, Eva-Lotta, Anders Biel, and Tommy Gärling. 2009. Knowledge and confidence in knowledge about climate change among experts, journalists, politicians, and laypersons. Environment and Behavior 41(2): 281-309.

Sunstein, Cass R. 2007. Of Montreal and Kyoto: A tale of two protocols. Harvard Environmental Law Review 31: 1-65.

Thompson, Mark. 2005. Editorial guidelines: The BBC's values and standards. Accessed at $<$ http://downloads.bbc.co.uk/guidelines/editorialguidelines/Legacy_Guidelines/2005-editorial-guidelinesfull.pdf > on March 1, 2013.

Tobacco Institute. Undated. Public smoking issue: Consulting scientists on ETS and IAQ. Tobacco Institute Document No. 0003162-0003164. Accessed at $<$ https://industrydocuments.library.ucsf.edu/tobacco/docs/\#id=gpmj0146> on June 5, 2015.

Toke, Dave. 1999. Epistemic communities and environmental groups. Politics 19(2): 97-102.

Toner, Mike. 2006. Climate change in 1900s biggest in a millennium; measurements at 14 locations show widespread warming. Philadelphia Inquirer, February 13, 2006.

Tuchman, Gaye. 1972. Objectivity as strategic ritual: An examination of newsmen's notions of objectivity. American Journal of Sociology 77(4): 660-679.

Vilella-Vila, Marta and Joan Costa-Font. 2008. Press media reporting effects on risk perceptions and attitudes towards genetically modified (GM) food. Journal of Socio-Economics 37(5): 2095-2106.

Walker, Joe. 1998. Draft global climate science communications plan. Accessed at $<\mathrm{http} / / /$ research.greenpeaceusa.org/?a=view\&d=4383> on October 30, 2013.

Williams, Mary E. 2011. Jenny McCarthy's autism fight grows more misguided. Salon, January 6, 2011. Accessed at <http://www.salon.com/2011/01/06/jenny_mccarthy_autism_debate/> on July 3, 2013.

Worlds of Journalism Study. 2007-2011. Datasets. Accessed at $<$ http://www.worldsofjournalism.org/download.htm> on October 4, 2013.

Yu, Zhihao. 2005. Environmental protection: A theory of direct and indirect competition for political influence. Review of Economic Studies 72(1): 269-286. 
Table 1: Belief and political knowledge by level of news consumption

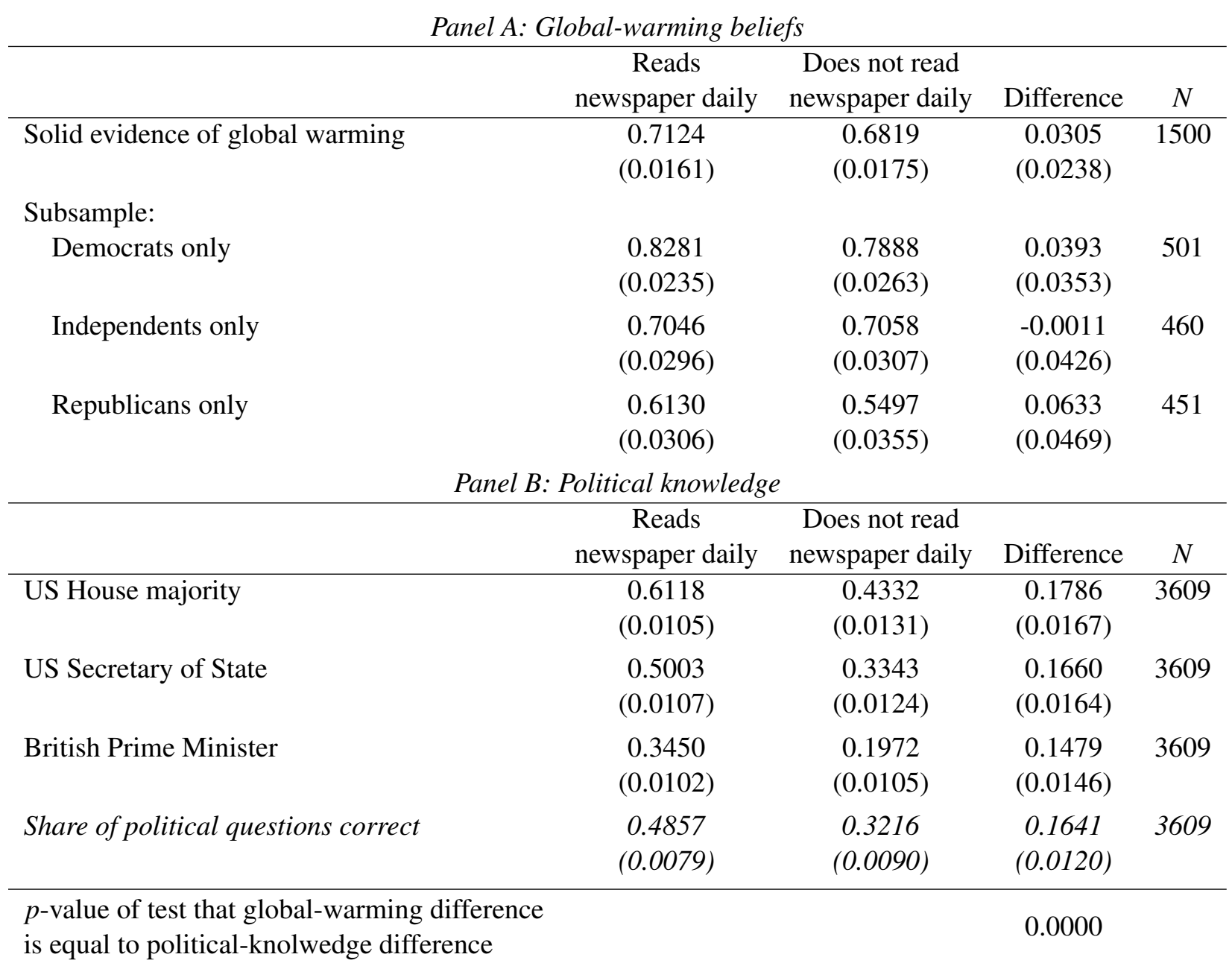

Note: Data are from the Pew Research Center for the People and the Press (2013). Data in panel A come from the June News Interest/Believability Survey (June 2006). The "reads newspaper daily" column consists of those who answer "yes" to the question "Some people are so busy that they don't get to read a newspaper every day. How about you - do you get a chance to read a newspaper just about every day, or not?" The "solid evidence of global warming" rows report respectively the fraction of all respondents, Democrats, Independents, and Republicans who answer "yes" to the question "From what you've read and heard, is there solid evidence that the average temperature on earth has been getting warmer over the past few decades, or not?" Democrats, Independents, and Republicans respectively consist of those who answer "Democrat", "Independent", and "Republican" to the question "In politics today, do you consider yourself a Republican, Democrat, or Independent?" Data in panel B come from the Biennial Media Consumption Survey (April 2008). The "reads newspaper daily" column consists of those who answer "yes" to the question "Do you happen to read any daily newspapers regularly, or not?" The "US House majority" row reports the fraction of respondents who answer "Yes, Democrat" to the question Do you happen to know which political party has a majority in the US House of Representatives?" The "US Secretary of State" row reports the fraction of respondents who answer "Yes, Condoleezza Rice/Condi/Rice" to the question "Can you tell me the name of the current US Secretary of State?" The "British Prime Minister" row reports the fraction of respondents who answer "Gordon Brown" to the question "Who is the current prime minister of Great Britain?" The "share of political questions correct" row is the share correct across the three political knowledge questions. The last row reports the $p$-value of the test that the global-warming difference is equal to the difference in the share of political questions correct. All calculations use recommended sample weights. Standard errors are reported in parentheses. 
Table 2: Belief and scientific knowledge by level of news consumption

\begin{tabular}{|c|c|c|c|c|}
\hline \multicolumn{5}{|c|}{ Panel A: Global-warming beliefs } \\
\hline & $\begin{array}{c}\text { Reads } \\
\text { newspaper daily }\end{array}$ & $\begin{array}{c}\text { Does not read } \\
\text { newspaper daily }\end{array}$ & Difference & $N$ \\
\hline \multirow[t]{2}{*}{ Solid evidence of global warming } & 0.7124 & 0.6819 & 0.0305 & 1500 \\
\hline & $(0.0161)$ & $(0.0175)$ & $(0.0238)$ & \\
\hline \multicolumn{5}{|c|}{ Panel B: Scientific knowledge } \\
\hline & $\begin{array}{c}\text { Follows } \\
\text { news closely }\end{array}$ & $\begin{array}{c}\text { Does not follow } \\
\text { news closely }\end{array}$ & Difference & $N$ \\
\hline Radiation sunscreen protects against & $\begin{array}{c}0.8810 \\
(0.0139)\end{array}$ & $\begin{array}{c}0.7875 \\
(0.0191)\end{array}$ & $\begin{array}{c}0.0935 \\
(0.0236)\end{array}$ & 1006 \\
\hline Nanotechnology deals with things that are ... & $\begin{array}{c}0.6945 \\
(0.0198)\end{array}$ & $\begin{array}{c}0.6025 \\
(0.0228)\end{array}$ & $\begin{array}{c}0.0920 \\
(0.0302)\end{array}$ & 1006 \\
\hline Major concern about overuse of antibiotics & $\begin{array}{c}0.8403 \\
(0.0157)\end{array}$ & $\begin{array}{c}0.7035 \\
(0.0213)\end{array}$ & $\begin{array}{c}0.1368 \\
(0.0265)\end{array}$ & 1006 \\
\hline Gas that causes temperatures to rise & $\begin{array}{c}0.6527 \\
(0.0204)\end{array}$ & $\begin{array}{c}0.5213 \\
(0.0233)\end{array}$ & $\begin{array}{c}0.1314 \\
(0.0310)\end{array}$ & 1006 \\
\hline Resource extracted in "fracking" & $\begin{array}{c}0.6249 \\
(0.0208)\end{array}$ & $\begin{array}{c}0.4080 \\
(0.0229)\end{array}$ & $\begin{array}{c}0.2169 \\
(0.0309)\end{array}$ & 1006 \\
\hline Share of scientific questions correct & $\begin{array}{c}0.7386 \\
(0.0120)\end{array}$ & $\begin{array}{c}0.6046 \\
(0.0138)\end{array}$ & $\begin{array}{c}0.1341 \\
(0.0183)\end{array}$ & 1006 \\
\hline $\begin{array}{l}p \text {-value of test that global-warming difference } \\
\text { is equal to scientific-knowledge difference }\end{array}$ & & & 0.0006 & \\
\hline
\end{tabular}

Note: Data are from the Pew Research Center for the People and the Press (2013). Data in panel A come from the June News Interest/Believability Survey (June 2006). The "reads newspaper daily" column consists of those who answer "yes" to the question "Some people are so busy that they don't get to read a newspaper every day. How about you - do you get a chance to read a newspaper just about every day, or not?" The "solid evidence of global warming" row reports the fraction of respondents who answered "yes" to the question "From what you've read and heard, is there solid evidence that the average temperature on earth has been getting warmer over the past few decades, or not?" Data in panel B come from the 2013 Omnibus Survey (March 2013). The "follows news closely" column consists of those who answer "very closely" or "fairly closely" to at least three of the following five questions: "Did you follow (i) reports about the condition of the US economy, (ii) automatic government spending cuts that began on March 1st, (iii) reports about the US stock market, (iv) the death of Hugo Chavez, the President of Venezuela, (v) Catholic cardinals meeting in Rome to select a new pope very closely, fairly closely, not too closely, or not at all closely?" The "radiation sunscreen protects against" row reports the fraction of respondents who answer "ultraviolet" to the question "Which one of the following types of solar radiation does sunscreen protect the skin from?" The "nanotechnology deals with things that are..." row reports the fraction of respondents who answer "small" to the question "Does nanotechnology deal with things that are extremely...?" The "major concern about overuse of antibiotics" row reports the fraction of respondents who answer "it can lead to antibiotic-resistant bacteria" to the question "Which of these is a major concern about the overuse of antibiotics?" The "gas that causes temperatures to rise" row reports the fraction of respondents who answer "carbon dioxide" to the question "What gas do most scientists believe causes temperatures in the atmosphere to rise?" The "resource extracted in "fracking" row reports the fraction of respondents who answer "natural gas" to the question "Which natural resource is extracted in a process known as 'fracking'?" The "share of scientific questions correct" row is the share correct across the five scientific knowledge questions. The last row reports the $p$-value of the test that the global-warming difference is equal to the difference in the share of scientific questions correct. All calculations use recommended sample weights. Standard errors are reported in parentheses. 


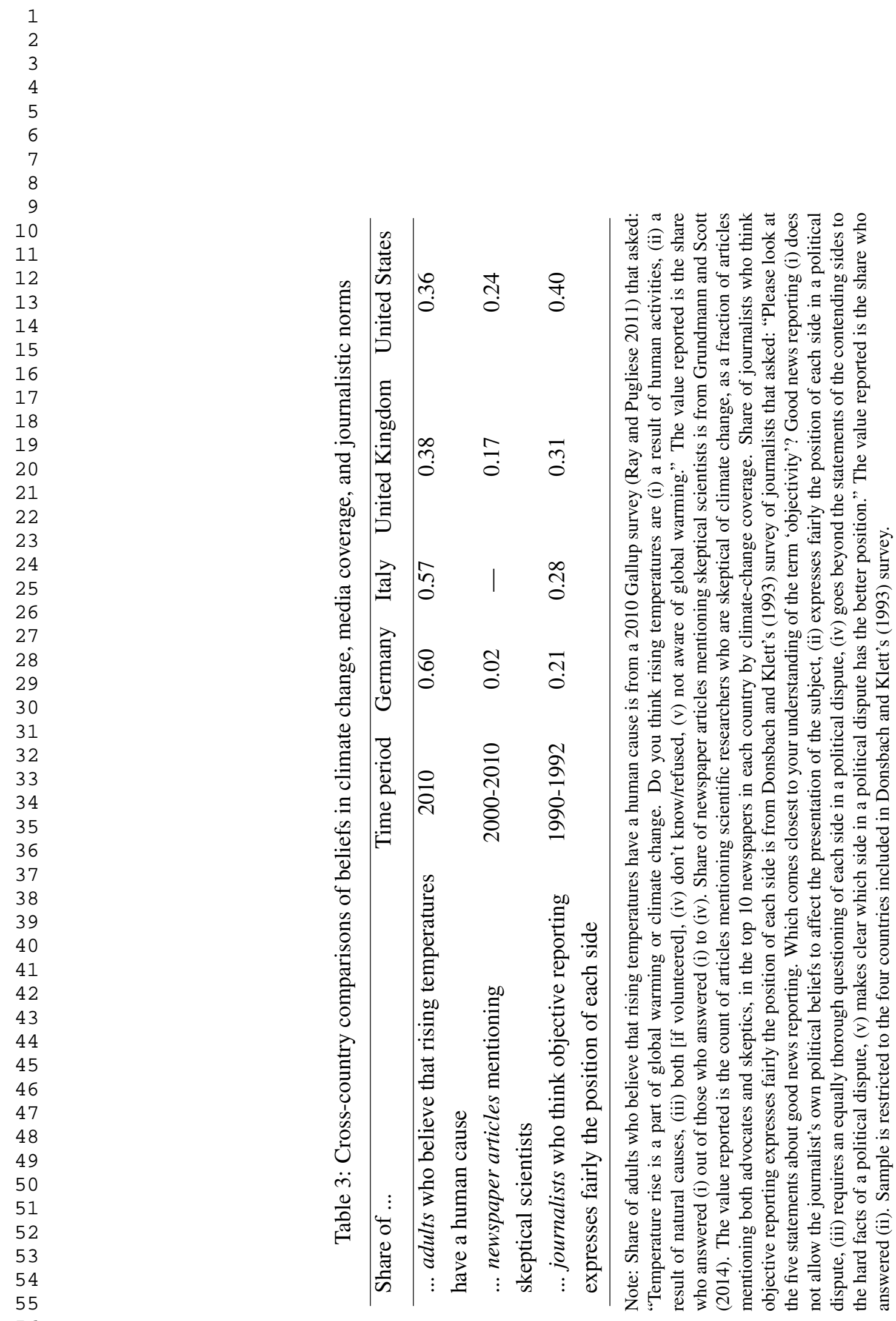

56

58 
Figure 1: Trends in public beliefs about climate change in the US

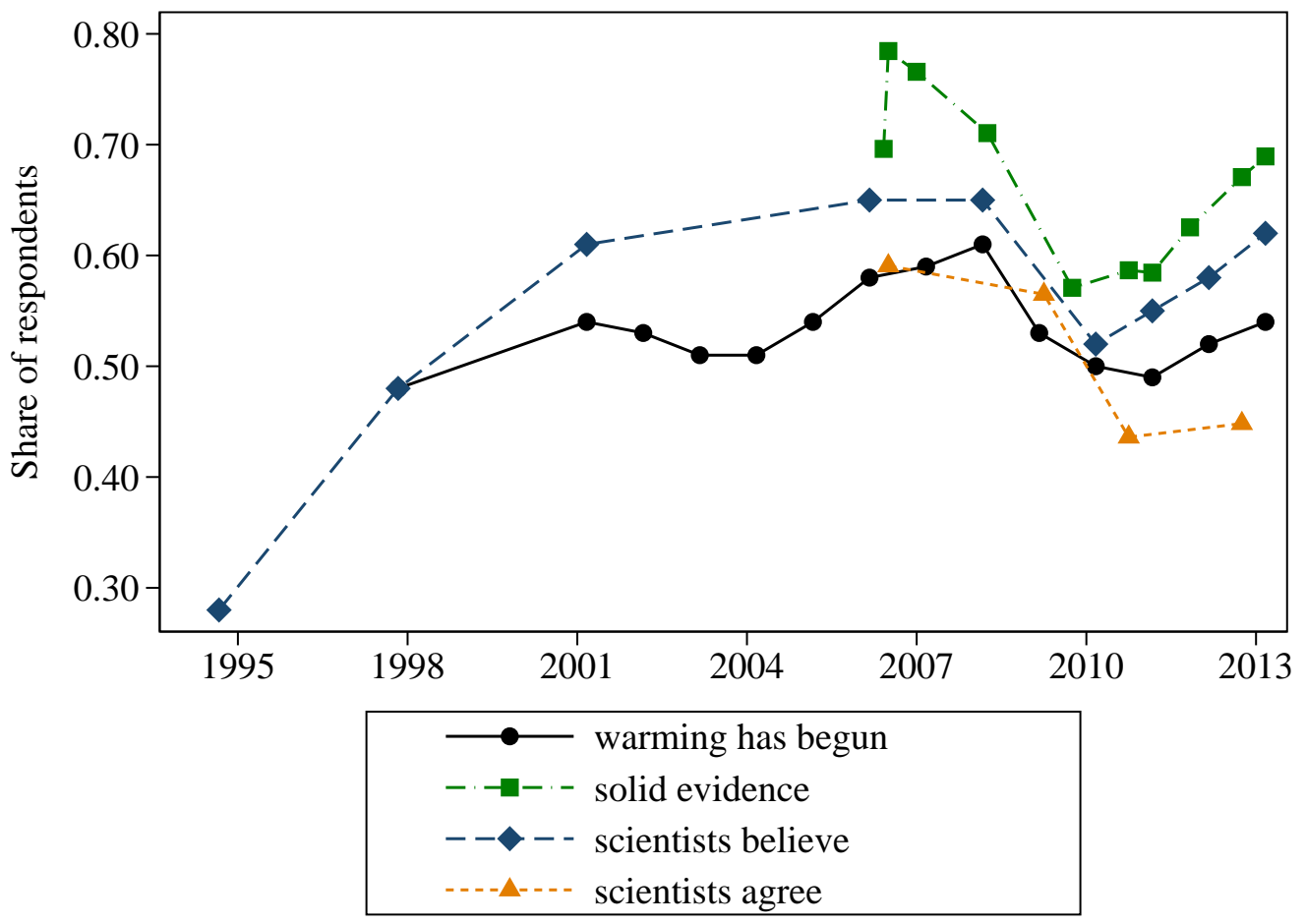

Notes: Series "warming has begun" is from Saad (2013). The series shows the share of respondents replying "they have already begun to happen" in response to the question "Which of the following statements reflects your view of when the effects of global warming will begin to happen? (i) they have already begun to happen, (ii) they will start happening within a few years, (iii) they will start happening within your lifetime, (iv) they will not happen within your lifetime, but they will affect future generations, or (v) they will never happen." Series "solid evidence" is from the Pew Research Center for the People and the Press (2013). Studies used are the June News Interest/Believability Survey (June 2006), the July Religion and Public Life Survey (July 2006), the January News Interest Index Survey (January 2007), the April Political Survey (April 2008), the October Political Survey (October 2009, October 2010, and October 2012), the March Political Typology Survey (March 2011), the November Religion and Politics Survey (November 2011), and the March Political Survey (March 2013). The series shows the share of respondents replying "yes" to the question "From what you've read and heard, is there solid evidence that the average temperature on earth has been getting warmer over the past few decades, or not?" Series "scientists believe" is from Nisbet and Myers (2007) and Saad (2013). The series shows the share of respondents replying "most scientists believe that global warming is occurring" in response to the question "On the environmental issue known as global warming, just your impression, which one of the following statements do you think is most accurate: (i) most scientists believe that global warming is occurring, (ii) most scientists believe that global warming is not occurring, or (iii) most scientists are unsure about whether global warming is occurring or not?" Series "scientists agree" is from the Pew Research Center for the People and the Press (2013). Studies used are the Religion and Public Life Survey (July 2006), the April General Public Science Survey (April 2009), and the October Political Survey (October 2010 and October 2012). The series shows the share of respondents replying "yes" to the question "From what you've heard or read, is there general agreement among scientists that the earth is getting warmer because of human activity, or not?" 
Figure 2: Climate-change beliefs across countries

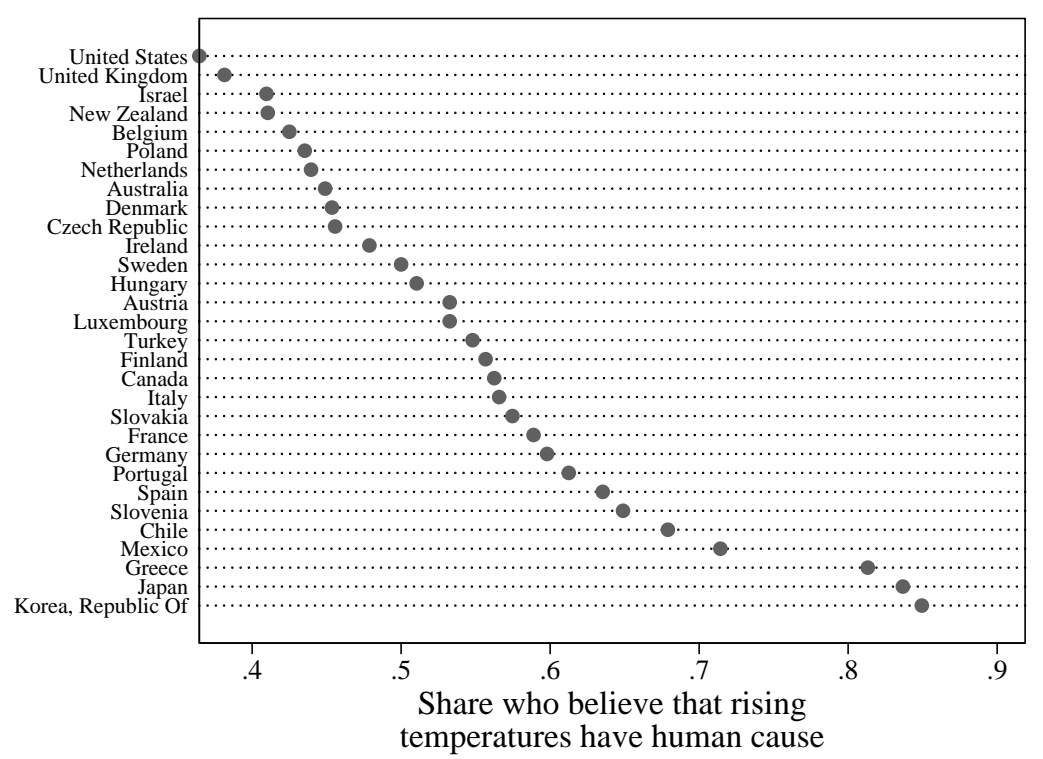

Note: Data are from a 2010 Gallup survey (Ray and Pugliese 2011) that asked: "Temperature rise is a part of global warming or climate change. Do you think rising temperatures are (i) a result of human activities, (ii) a result of natural causes, (iii) both [if volunteered], (iv) don't know/refused, or (v) not aware of global warming." The plot shows the share who answered (i) out of those who answered (i) to (iv). Sample is restricted to OECD countries. 


\section{A Robustness}

\section{A.1 The Parties Do Not Know the Journalist's Type}

Suppose that the parties do not know the journalist's leaning or type. Second-period play is unchanged from the analysis in section 4. In the first period, because the parties benefit from claiming only when the journalist is strategic, the incentive to claim is governed by equation (2) but with $\frac{k}{\eta_{s} v}$ in place of $\frac{k}{v}$. The characterization in proposition 1 applies with the same substitution. It follows that:

Proposition A.1. In an interior equilibrium, i.e. if $\Delta(0)>\frac{k}{\eta_{s} v}>\Delta(1)$, the policy distortion $\Phi$ is strictly decreasing in $\frac{k}{v}$ and strictly increasing in $\gamma$.

Turning to the strategic distortion, note that if $\frac{k}{\eta_{s} v}>\frac{k}{v} \geq \frac{1}{2}$, then $\rho^{*}=0$. Next suppose that $\frac{k}{v}<\frac{1}{2}$ and pick some $\eta_{h}>0$ such that $\frac{k}{\left(1-\eta_{h}\right) v}<\frac{1}{2}$. Then following the arguments in section 4 there exists some $\bar{\eta}_{c}\left(\eta_{h}\right)>0$ such that $\rho^{*}=1$ for all $\eta_{c}<\bar{\eta}_{c}\left(\eta_{h}\right)$. Because $\frac{k}{\left(1-\eta_{h}\right) v}$ is strictly increasing in $\eta_{h}$, it follows that:

Proposition A.2. The strategic distortion $\Phi_{0}$ is equal to $\frac{1}{4} \gamma$ if $\frac{k}{v}<\frac{1}{2}$ and 0 otherwise.

\section{A.2 The Captured Journalist has a Constrained Message Space}

Suppose that the captured journalist reports $m \subseteq\left(\sigma \cup j^{*}\right)$ according to the ordering $\lambda \succ\{l, r\} \succ \sim \lambda$, where $\sim \lambda$ denotes the complement to $\lambda$.

Begin with the second period. If the journalist is not captured, then she reports $m=\sigma$ and the parties do not claim. If the journalist is captured, then the parties may choose to claim. For any claiming probabilities, the report of the captured journalist is a garbling of the report of the non-captured journalist. Therefore the payment to the journalist at the beginning of the second period is strictly decreasing in $\hat{\eta}_{c}(m, \omega)$ in any equilibrium. An equilibrium in the second period can be shown to exist for any $\hat{\eta}_{c}(m, \omega) .{ }^{40}$

Turn next to the first period. The captured journalist will never report $m=\{l, r\}$ because if $m=\{l, r\}$ is an option then so is $m=\lambda$. Because the honest journalist reports $m=\{l, r\}$ with positive probability, $\hat{\eta}_{c}(\{l, r\}, \omega)=0$ in any equilibrium. And because all combinations of $(m, \omega)$ for singleton $m$ occur with positive probability for the captured journalist, $\hat{\eta}_{c}(l, \omega), \hat{\eta}_{c}(r, \omega)>0$ in any equilibrium. It is therefore a dominant strategy for the strategic journalist to report $m=\{l, r\}$ whenever possible.

Party $j$ claims only if $\sigma=\sim j$. If the journalist is strategic, then party $j$ is willing to claim if and only if the condition in equation (2) holds. If the journalist is captured, then party $j$ is willing to claim if and only if

$$
\frac{1}{2}(\operatorname{Pr}(\omega=j \mid m=j)-\operatorname{Pr}(\omega=j \mid m=\sim j)) \geq \frac{k}{v} .
$$

\footnotetext{
${ }^{40}$ Fix $\hat{\eta}_{c}(m, \omega)$ at some value $\hat{\eta}_{c} \in(0,1]$. It suffices to show the existence of a symmetric equilibrium in which each party $j$ claims with probability $\varphi$ when the journalist is captured and $\sigma=\sim j$. Each party $j$ is willing to claim if and only if

$$
\frac{1}{2}(\operatorname{Pr}(\omega=j \mid m=j)-\operatorname{Pr}(\omega=j \mid m=\sim j)) \geq \frac{k}{v}
$$

or equivalently

$$
\operatorname{Pr}(\omega=j \mid m=j)-\frac{1}{2} \geq \frac{k}{v}
$$

where by Bayes' Rule:

$$
\operatorname{Pr}(\omega=j \mid m=j)=\frac{\left(1-\hat{\eta}_{c}\right) \gamma+\hat{\eta}_{c} \frac{1}{2}}{\left(1-\hat{\eta}_{c}\right) \gamma+\hat{\eta}_{c} \frac{1}{2}+\hat{\eta}_{c} \frac{1}{2}((1-\gamma)+\gamma \varphi)} .
$$

Observe that $\operatorname{Pr}(\omega=j \mid m=j)$ is strictly decreasing in $\varphi$, from which existence of a (unique) equilibrium value of $\varphi^{*}$ is immediate.
} 
No party claims if the journalist is honest.

It is immediate that $\operatorname{Pr}(\omega=j \mid m=j)-\operatorname{Pr}(\omega=j \mid m=\sim j)<1$. It then follows from equation (6) that if $\frac{k}{v} \geq \frac{1}{2}$ the parties do not claim when the journalist is captured. From equation (2) and the symmetry of the parties' incentives, it can be shown that the parties do not claim when the journalist is strategic.

It is also straightforward to show that $\operatorname{Pr}(\omega=j \mid m=j)-\operatorname{Pr}(\omega=j \mid m=\sim j)$ has a lower bound that is decreasing in $\eta_{c}$ and that approaches 1 as $\eta_{c}$ approaches $0 .{ }^{41}$ It follows from equation (6) that if $\frac{k}{v}<\frac{1}{2}$ then there exists $\bar{\eta}_{c}>0$ such that if $\eta_{c}<\bar{\eta}_{c}$ both parties invest with certainty when the journalist is captured. In this case the captured journalist always reports $m=\lambda$, and equilibrium outcomes in the first period are equivalent to those in the baseline game.

An implication is that:

Proposition A.3. The strategic distortion $\Phi_{0}$ is equal to $\frac{1}{4} \gamma$ if $\frac{k}{v}<\frac{1}{2}$ and 0 otherwise.

\section{A.3 There Are Many Competing Journalists}

Suppose that there are finitely many competing journalists. Types and leanings are i.i.d. across journalists with the same probabilities as in the baseline game. In each period the voter receives the report of a single journalist of her choice, and the chosen journalist receives a payment.

Rather than specifying a market institution, I assume only that, before the voter has made her choice, the expected payment to each journalist is strictly decreasing in the expected reduction in the voter's loss $L(a, \omega)$ from receiving that journalist's report. As a concrete example, we may imagine that the voter chooses among journalists to minimize the expected sum of her loss $L(a, \omega)$ and a privately known type I extreme value utility shock, and that the journalist chosen by the voter receives a fixed and strictly positive advertising revenue.

In the second period, in any equilibrium the chosen journalist reports $m=\lambda$ if she is captured and $m=\sigma$ otherwise, so the parties will not claim. Therefore the expected payment to a given journalist in the second period is strictly decreasing in the voter's posterior belief that the journalist is captured.

In the first period, consider some journalist who is chosen with positive probability in some equilibrium. Because for this journalist all combinations of $(m, \omega)$ occur with positive probability on the equilibrium path, the voter assigns probability 0 to the event that the journalist is captured if $m=\{l, r\}$ and strictly positive probability otherwise. Therefore it is a strictly dominant strategy for the journalist to report $m=\{l, r\}$ whenever possible if she is strategic.

The above shows that, in each period, the strategic journalist behaves as in the baseline model. Equilibrium existence is immediate because the assumptions on journalists' payoffs imply a well-defined choice process for the voter in the first period. It therefore follows that:

\footnotetext{
${ }^{41}$ Recall that $\rho_{j}$ is the probability that party $j$ claims if the journalist is strategic. Let $\varphi_{j}$ be the analogue when the journalist is captured. By Bayes' Rule:

$$
\begin{aligned}
\operatorname{Pr}(\omega=j \mid m=j) & =\frac{\eta_{h} \gamma+\eta_{s} \gamma\left(1-\rho_{\sim j}\right)+\eta_{c} \frac{1}{2}}{\eta_{h} \gamma+\eta_{s} \gamma\left(1-\rho_{\sim j}\right)+\eta_{c} \frac{1}{2}+\eta_{c} \frac{1}{2}\left((1-\gamma)+\gamma \varphi_{j}\right)} \\
\operatorname{Pr}(\omega=j \mid m=\sim j) & =\frac{\eta_{c} \frac{1}{2}\left((1-\gamma)+\gamma \varphi_{\sim j}\right)}{\eta_{h} \gamma+\eta_{s} \gamma\left(1-\rho_{j}\right)+\eta_{c} \frac{1}{2}+\eta_{c} \frac{1}{2}\left((1-\gamma)+\gamma \varphi_{\sim j}\right)} \\
\operatorname{Pr}(\omega=j \mid m=\{l, r\}) & =\frac{1}{2} \frac{\eta_{h}(1-\gamma)+\eta_{s}\left((1-\gamma)+\gamma \rho_{\sim j}\right)}{\eta_{h}(1-\gamma)+\eta_{s}\left((1-\gamma)+\gamma\left(\frac{1}{2} \rho_{\sim j}+\frac{1}{2} \rho_{j}\right)\right)}
\end{aligned}
$$
}

where I include the last expression for completeness. We then have that

$$
\operatorname{Pr}(\omega=j \mid m=j)-\operatorname{Pr}(\omega=j \mid m=\sim j) \geq \frac{\eta_{h} \gamma}{\eta_{h} \gamma+\eta_{c}} .
$$


Proposition A.4. In any equilibrium of the game with competing journalists, in each period the joint distribution of $(m, \omega)$ is identical to that in the equilibrium of the baseline game.

An immediate corollary is that:

Corollary A.1. In any equilibrium of the game with competing journalists, the policy distortion is identical to that in the baseline game.

That is, the game with competing journalists inherits the comparative statics of the baseline game derived in section 4 . Note that the arguments above are valid whether or not the parties know the identity of the chosen journalist, so I have intentionally left this detail unspecified.

\section{A.4 There Are Many Periods}

Suppose the game is played in each of $T$ periods with the states $\omega_{t}$ revealed at the end of the game. With probability $\eta_{c} \in(0,1)$ the journalist is captured. With probability $\left(1-\eta_{c}\right)$ the journalist is strategic. In each period, independently with probability $\eta_{h} \in(0,1)$ the journalist reports $m=\sigma$ regardless of her type. Other details follow the baseline game.

Let $\hat{\eta}_{c}^{t}$ be the voter's belief that the journalist is captured as of the beginning of period $t$. Observe that in any equilibrium $\hat{\eta}_{c}^{t} \in(0,1)$ for any history of messages; moreover by Bayes' Rule there is $\bar{\eta}_{c} \in(0,1)$ with $\lim _{\eta_{c} \rightarrow 0} \bar{\eta}_{c}=0$ such that $\hat{\eta}_{c}^{t}<\bar{\eta}_{c}$ in any period $t$ in any equilibrium. ${ }^{42}$

For $\frac{k}{v}<\frac{1}{2}$ and $\eta_{c}$ sufficiently small, it is an equilibrium for the strategic journalist to report $m=\{l, r\}$ whenever possible and for the parties to claim with certainty in all periods $t<T$.

To see this, note first that, because the parties are short-run players, if the journalist reports $m=\{l, r\}$ whenever possible in some period $t$, then the parties' payoffs are analogous to those in the first period of the baseline game. In particular, for $\frac{k}{v}<\frac{1}{2}$ and $\hat{\eta}_{c}^{t}$ sufficiently small, both parties claim with certainty in equilibrium. Because $\hat{\eta}_{c}^{t}$ is uniformly bounded by a constant that diminishes to 0 as $\eta_{c} \rightarrow 0$, for for $\frac{k}{v}<\frac{1}{2}$ and $\eta_{c}$ sufficiently small the parties will claim with certainty in any period in which the journalist plays the conjectured strategy.

Next, note that in any equilibrium, in period $T$ the strategic journalist reports $m=\sigma$ and the parties do not claim. The journalist's payoff in period $T$ is therefore some $\pi_{T}\left(\hat{\eta}_{c}^{T}\right)$, where $\hat{\eta}_{c}^{T}$ is the voter's belief that the journalist is captured and $\pi_{T}()$ is some strictly decreasing function.

What remains is to show that, in the conjectured equilibrium, the strategic journalist wishes to report $m=\{l, r\}$ whenever possible in any period $t<T$. Begin with period $T-1$. For any $\hat{\eta}_{c}^{T-1} \in(0,1), \hat{\eta}_{c}^{T}$ is lower following a report of $m=\{l, r\}$ than following a report of $m=l$ or $m=r{ }^{43}$ Therefore in period $T-1$ the strategic journalist reports $m=\{l, r\}$ whenever possible. It follows that the journalist's payoff in period $T-1$ is some $\pi_{T-1}\left(\hat{\eta}_{c}^{T-1}\right)$, where $\pi_{T-1}()$ is strictly decreasing. ${ }^{44}$ The same argument then applies in period $T-2$, and so on.

\footnotetext{
${ }^{42}$ Let $\mathscr{C}$ be the event that the journalist is captured. Pick some period $t$ and history of messages $g$. It is sufficient to establish an upper bound on $\operatorname{Pr}(g \mid \mathscr{C}) / \operatorname{Pr}(g \mid \sim \mathscr{C})$ that does not depend on $\eta_{c}$. Clearly $\operatorname{Pr}(g \mid \mathscr{C}) \leq 1$ so it remains to establish a lower bound on $\operatorname{Pr}(g \mid \sim \mathscr{C})$. In any given period no message can occur less often than $z=\eta_{h} \min \left(\frac{1}{2} \gamma, 1-\gamma\right)$, and because "honest" reporting is i.i.d. across periods this means that $\operatorname{Pr}(g \mid \sim \mathscr{C}) \geq z^{t} \geq z^{T}$.

${ }^{43}$ This follows from Bayes' Rule and the fact that both honest reporting and the journalist's leaning are independent across periods.

${ }^{44}$ The reporting structure with some $\underline{\hat{\eta}}_{c}^{T-1}$ is a garbling of the reports with $\underline{\hat{\eta}}_{c}^{T-1}<\underline{\hat{\eta}}_{c}^{T-1}$, because the voter can always mimic the report of the captured type by flipping a fair coin with an appropriate probability following message $m=\{l, r\}$. Mathematically the voter's expected loss in period $T-1$ is

$$
\left(\eta_{h}(1-\gamma)+\left(1-\eta_{h}\right)\left(1-\hat{\eta}_{c}^{T-1}\right)\right) \frac{1}{4}+\frac{\left(\eta_{h} \gamma+\left(1-\eta_{h}\right) \hat{\eta}_{c}^{T-1} \frac{1}{2}\right)\left(\left(1-\eta_{h}\right) \hat{\eta}_{c}^{T-1} \frac{1}{2}\right)}{\eta_{h} \gamma+\left(1-\eta_{h}\right) \hat{\eta}_{c}^{T-1}},
$$

which is easily shown to be strictly increasing in $\hat{\eta}_{c}^{T-1}$.
} 
To summarize:

Proposition A.5. For $\frac{k}{v}<\frac{1}{2}$ and $\eta_{c}$ sufficiently small, it is an equilibrium outcome for the strategic journalist to report $m=\sigma$ in period $T$ and $m=\{l, r\}$ in all other periods.

It is immediate that the analogue of the strategic distortion for this equilibrium is $\frac{1}{4} \gamma$ in all periods $t<T$ and 0 in period $T$. 
Appendix Figure 1: Journalistic norms and climate-change beliefs across countries

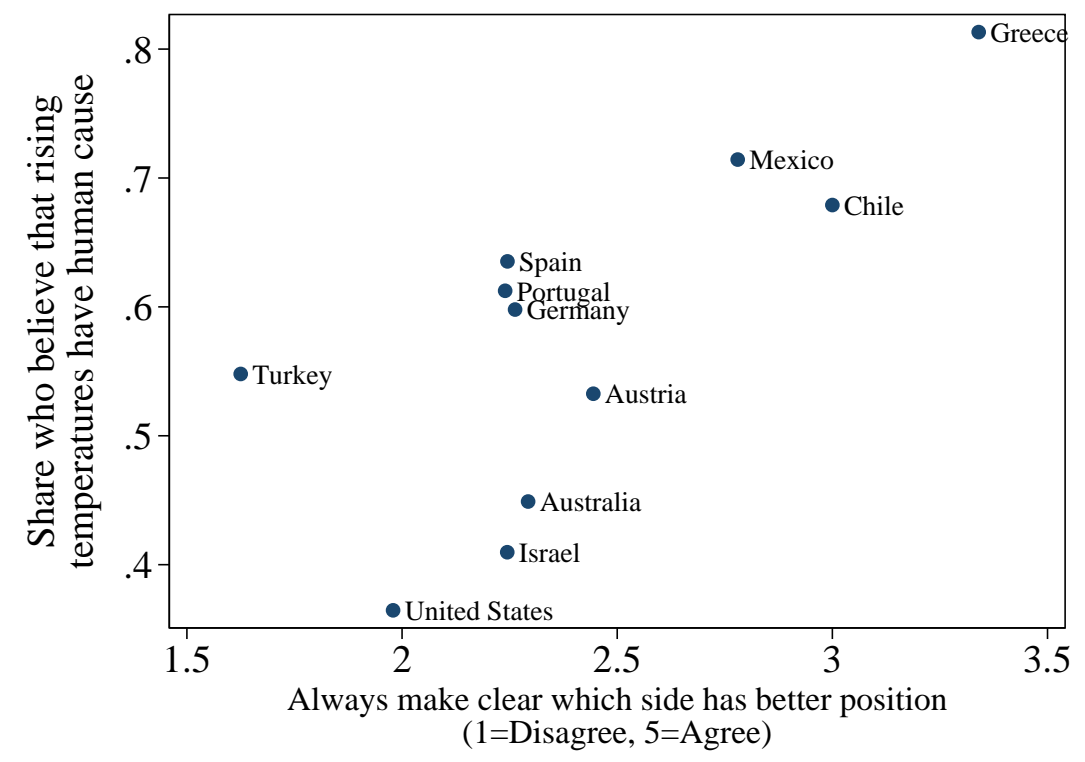

Note: Data for the y-axis are from a 2010 Gallup survey (Ray and Pugliese 2011) that asked: "Temperature rise is a part of global warming or climate change. Do you think rising temperatures are (i) a result of human activities, (ii) a result of natural causes, (iii) both [if volunteered], (iv) don't know/refused, or (v) not aware of global warming." The y-axis is the share who answered (i) out of those who answered (i) to (iv). Data for the x-axis are from the 2007-2011 Worlds of Journalism Study survey of journalists. The $\mathrm{x}$-axis is the average rating on a 1 (strongly disagree) to 5 (strongly agree) scale of the statement "I always make clear which side in a dispute has the better position." Sample is restricted to OECD countries. 